\title{
SUBSISTENCIA Y DESCAPITALIZACION EN EL CAMERO VIEJO AL FINAL DEL ANTIGUO REGIMEN
}

\author{
José Luis Gómez Urdáñez*
}

\begin{abstract}
RESUMEN
José Luis Gómez Urdáñez ha estudiado la agricultura camerana con el fin de demostrar su importancia, cuando los estudios básicos sobre la zona se han referido sobre todo a la ganadería. Hace notar el papel de amortiguador de la producción agricola y el desigual reparto de la propiedad ganadera, asi como el peso de la descapitalización impuesta por los grandes propietarios ganaderos, tres factores claves para entender la crisis económica camerana entre mediados del siglo XVIII y primer tercio del XIX.
\end{abstract}

\section{SUMMARY}

José Luis Gómez Urdáñez has studied the cameran state of agriculture, seeking to prove its weight. He notices the cushioning rol of agricultural production and uneven distribution of stock property; he also mentions the importance of the decapitalization imposed by the great livingstock owners, three key factors to the understanding of the Cameran economic crisis between the second half of 18 th century and the first third of the 19th century.

Los estudios recientes sobre la crisis camerana y los que, de forma general, han abordado la problemática ganadera del textil a finales del Antiguo Régimen ${ }^{1}$ permiten reforzar algunas

* Dpto. de Historia Moderna y Contemporánea. Colegio Universitario de La Rioja.

1. Entre los que contienen referencias más amplias a los temas tratados en este estudio, GARCIA SANZ, A., Desarrollo y crisis del Antiguo Régimen en Castilla la Vieja..., Madrid, 1974; «La agonía de la Mesta...», Agricultura y Sociedad, enero-marzo, 1978, 283-356; «Algo más sobre el final de la Mesta y la

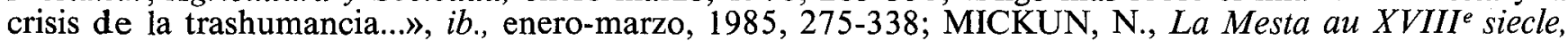
Budapest, 1983; BUSTOS RODRIGUEZ, M., «Campomanes y la Mesta. La nueva coyuntura del siglo XVIII», Hispania, Madrid, 1980, n. ${ }^{\circ}$ 114, 129-152. Marqués del SALTILLO, "Ganaderos sorianos en el siglo XVIII», Celtiberia, Soria, 1952, n. ${ }^{\circ}$ 2. GONZALEZ ENCISO, A., «La protoindustria en Castilla la Vieja en el siglo XVIII», Revista de Historia Económica, II, 3, 1984, y «La industria dispersa en la Sierra de Cameros, 1700-1840», Actas del I Coloquio de Historia de La Rioja, CUR, 1984, X, 1, 39-56. OCHA GAVIA, D., Historia textil Riojana, Logroño, 1975-6. LAZARO RUIZ, M., «Torre de Cameros: la movilidad de población...», Actas del I Coloquio..., CUR, 1984, X, i, 71-90. GURRIA GARCIA, P., «Observaciones sobre la estructura familiar camerana...», ib., 57-70. C. de CAMPOMANES, Respuesta del Sr. Fiscal... en vista de las instancias hechas por la provincia de Extremadura, quejándose de los daños que causaban los ganaderos trashumantes. Madrid, 1770. 
conclusiones relativas a la disminución de la cabaña, a la crisis de la industria textil y a la caída de la población. La interacción de estos factores, los más estudiados, ha servido para explicar el proceso crítico mediante una férrea lógica causal: al disminuir la cabaña de ganado lanar, se contrae la producción textil y se produce una reducción ocupacional en ambos sectores por la cual el binomio recursos-población se rompe en perjuicio de ese siempre inestable equilibrio demográfico antiguorregimental. Las consecuencias en que más se ha insistido, tan lógicas como demostrables, son la emigración, la reducción de los servicios en los pueblos que pierden más población, y una situación de empobrecimiento general a causa de la caída de los sectores más monetarizadores de la economía de las sierras. Las abundantes manifestaciones de los contemporáneos, a quienes no escapó la relación de los factores negativos cuando criticaban los decretos reformistas de los años sesenta- el factor desencadenante más evidente- refuerzan el esquema: «se seguirán graves perjuicios y daños a este país -decía la cuadrilla de Laguna en 1768- pues se verán precisados los ganaderos a desertar las (sierras) y pasar su habitación a la provincia de Extremadura y lo mismo los pastores y criados por no haber en este país otro modo de vivir por lo árido y frío, y de aquí se seguirá que las iglesias se perderán, pues no habiendo de verano con que enciemar, las pocas tierras que se cultivan se quedarán incultas, y los pueblos sin vecinos, por lo que también se desfalcarán las contribuciones reales...» ${ }^{2}$. Los temores se harán realidad, pero, conforme avanza el siglo, irán apareciendo entre las causas otros factores de coyuntura además de los estructurales originados por la reducción de la cabaña ganadera.

Ajamil en 1798, San Román, Velilla, Montalbo y Santa María en 1799, no pueden mantener un cirujano como hasta entonces habían tenido. Torre, en 1795, se queja de la falta de maestro; el último han tenido que despedirlo por falta de dinero en el año anterior. Hay muchos más casos en que se constata la pérdida de servicios, pero en todos las causas esgrimidas ya no son sólo las generales de mediados de siglo. Ahora son «los malos años y carestía de bastimentos» o «hallarsen muy recargados los vecinos de modo que aun para cobrar lo que hasta aquí han pagado (al cirujano) ha llegado muchas veces al caso de verse la justicia en la dura precisión de hacerles embargar a sus pobres vecinos» (en Ajamil)³.

Las malas cosechas, los precios elevados de los cereales -sobre todo en las crisis de 1792-95 y 1802-1805- (véanse gráf. 12 y 13 sobre los precios en los dos mercados más importantes del Camero Viejo) o las guerras están presentes entre las razones que esgrimen los concejos -no ya los grandes ganaderos- para explicar el empobrecimiento que denota la pérdida de servicios. Las malas cosechas y los altos precios del trigo en esos años pesaban en las economías menos estables -las primordialmente agrarias-, igual que las guerras -entre otros factores como el alza de costos de mantenimiento o el desplazamiento de las dehesas extremeñas de los ganados cameranos- en las privilegiadas de la «aristocracia ganadera». El acuerdo entre un vecino de Laguna que arrienda 2.875 cabezas de lanar a uno de Gibraleón, en 1807, puede servir como ejemplo: el precio por cabeza es 4 reales al año «durante la guerra con Inglaterra, y verificada que sea la paz de aquélla con España, en el tiempo de este arriendo, pagará a seis reales por cabeza». En 1795, el rico D. Juan Manuel Crespo escribía «el porteo de las sacas (de la lana) ha estado en calma con motivo de las guerras en este presente año» ${ }^{4}$.

El esquema de la crisis se complica a medida que introducimos otros factores, mucho menos estudiados, cuyo análisis no puede cuestionar la constatada tendencia a la baja de los indicadores relativos a ganadería y población, pero sí puede orientar sobre la causalidad y -más importante- sobre las variadas consecuencias de la crisis -el impacto diferencial en las clases

2. La cuadrilla de Laguna en 1768. AHPLo (Archivo Histórico de Protocolos de Logroño), Gaona, 28 de marzo de 1768, f. 12.

3. Ib., Gaona, 1795 , ff. 35 y ss. y 1799, f. 31, sobre Ajamil, Sta. María, Velilla, Montalbo y S. Román, Herreros de Tejada, 1795, f. 49, sobre Torre. Tam, Gaona, 1799, f. 41.

4. $I b$., Herreros de Tejada, 1807 , f. 54 y Gaona, 1795 , f. 33 , respectivamente. 
sociales- y de los intentos de superarla en el largo proceso. La agricultura camerana, olvidada hasta ahora, tiene ahí un lugar preferente.

\section{La agricultura en el Camero Viejo}

Si además de constatar la disminución de ganado en la sierra del Camero Viejo observamos la tendencia general producida igualmente a la baja en el valle riojano, resultará evidente el paralel ismo del proceso. Tomemos el caso de Murillo de río Leza ${ }^{5}$, un pueblo del valle, con amplia jurisdicción, y unos 200 vecinos en el catastro de Ensenada, y comparemos el total de ganado lanar con el de pueblos serranos, a mediados del siglo XVIII ${ }^{6}$.

\section{Estantes}

Murillo

Hornillos

Muro

San Román

Soto
6.558

4.356

3.229

898

4.540

\section{Trashumantes}

267

268

1.130

709

Un pueblo como Soto, que tiene casi el triple de población que Murillo, tiene menos cabezas de ganado. Muro, con la mitad de población, daría un resultado proporcional por vecino. Observemos la evolución de la cabaña a lo largo del período:

$\begin{array}{cccc} & 1753 & 1761 & 1795 \\ \text { Murillo } & 6.558 & 4.931 & 2.000\end{array}$

Y los datos extremos de que dispongo para los pueblos cameranos ${ }^{7}$ :

$1750 \quad 1828-29$

$\begin{array}{llr}\text { Hornillos } & 4.623 & 2.579 \\ \text { Muro } & 3.497 & 1.248 \\ \text { San Román } & 2.028 & 619 \\ \text { Soto } & 5.249 & 2.200\end{array}$

Es constatable que el proceso de reducción de la cabaña no afecta sólo a las sierras, pero es más difícil la comparación de los efectos. Podría decirse que en un valle fértil como el que rodea a Murillo la ampliación de la superficie cultivada habría limitado los efectos de la disminución ganadera. Por lo que sabemos, la extensión cultivada en Murillo pasó de 9.800

5. Los datos sobre Murillo de río Leza proceden de la tesis de licenciatura de Juan Luis PASTOR OCON, Transformaciones económicas en Murillo (La Rioja), 1750-1833, leída en el Dpto. de Historia Moderna y Contemporánea de la U. de Zaragoza, en setiembre de 1986.

6. AHPLo., Sec. Catastro, Respuestas generales.

7. AHPLo. Los datos de 1818-29 y 1832 se encuentran en copias de informes enviados a la Mesta desde la escribanía de Gaona. Con estos papeles se hicieron las guardas de las encuadernaciones de los legajos de los años 1769 a 1794. 
fanegas en 1750 a 11.374 en 1820 , un incremento de 1.574 fanegas entre los dos extremos cronológicos, mientras la población aumentó en unos cincuenta vecinos. Pero veamos el uso de la tierra en los dos cultivos más practicados en el valle medio en $1750^{8}$ :

$\begin{array}{lcc}\text { Murillo } & 3.771 \text { fan. } & 2.090 \text { fan. } \\ \text { Ocón (con aldeas) } & 4.400 » & 400 » \\ \text { Alberite } & 3.434 » & 2.398 »\end{array}$

Y en la zona más dedicada al vino:

$\begin{array}{lrr}\text { Briones } & 2.788 & 5.700 \\ \text { San Vicente de la Sonsierra } & 900 & 5.700 \\ \text { Cenicero } & 3.229 & 3.030\end{array}$

En síntesis, si hacemos una media de la extensión de cereal por vecino, tendremos:

$\begin{array}{lrc}\text { Murillo } & 15 & \text { fan./vec. } \\ \text { Alberite } & 23,5 & \text { " } \\ \text { Cenicero } & 12,9 & \text { » } \\ \text { Briones } & 9,2 & \text { ” } \\ \text { San Vicente } & 2,9 & \end{array}$

Para nuestro propósito habría que comparar con las precauciones obvias los dos productos principales de las dos zonas -vino y ganadería- en el sentido de que ambas precisan no sólo la producción de una materia prima sino también su elaboración, almacenamiento y comercialización hacia fuera; habría que tener en cuenta además las constatadas crisis en la comercialización de ambos productos ${ }^{9}$ y las estructuras que imponían en lo relativo a la concentración de la propiedad, de medios y a la disponibilidad de una mano de obra abundante y no permanente. Aceptando pues que las coyunturas negativas contraían la comercialización de estos dos productos en la medida en que son prescindibles cuando las subsistencias no están aseguradas, podremos precisar, sirviéndonos de las posibilidades de comparación con el valle, los niveles de subsistencia y el papel de la agricultura en la sierra del Camero Viejo. Comparemos para ello

8. Los datos sobre Ocón proceden de la elaboración del catastro realizada para su tesis de licenciatura en curso por P. L. LORENZO CADARSO; los de Briones y San Vicente, de la que realiza R. PALACIOS CUESTA; los de Alberite, de BAIGORRI JALON, J., «Alberite en el siglo XVIII (Análisis del catastro de la Ense nada), Berceo, 91, 1976, 207-226. Y los de Cenicero de mi estudio sobre la economía y la sociedad de esta localidad, que se publicará en el trabajo colectivo Cenicero Histórico Transformaciones económicas y camb ios sociales en una ciudad riojana.

9. Sobre el vino en la otra ribera riojana, FERNANDEZ DE PINEDO, E., Crecimiento económico y transformaciones sociales en el País Vasco (1100-1850), Madrid, 1974. Tam., HUETZ DE LEMPS, A., Vignob les et vins du nord ouest de l'Espagne, Bordeaux, 1967, espec. pp. 411 y ss. y mi trabajo en Cenicero Histórico... Sobre los productos ganaderos, espec. las ob. cit. de GARCIA SANZ y GONZALEZ ENCISO. 
Fan. dedic. a

cereal

10.117

1.280

2.667

1.504

1.683

1.320

1.012

1.231

559

525

645

1.393

1.240

$1.358,7$

883

2.400 \%del término

fan./vec.

21,0

29,4

12,0

21,5

38,3

11,2

34,5

10,2

26,0

17,1

35,9

25,2

20,2

24,8

51,1

32,4
41,9

26,1

33,4

6,3

14,1

14,2

13,0

15,0

16,5

13,3

24,8

22,2

13,7

11,5

Esta comparación nos permite apreciar que la media de tierra destinada a cereal por vecino es superior en muchas localidades cameranas con respecto a las que en el valle alternaban cereal y viña. Sólo es notablemente inferior en los pueblos donde se concentró la industria textil (Soto, San Román, Munilla y Laguna), que albergaban además las más altas concentraciones de población (Soto, con más de 500 vecinos, tenía en 1750, más población que Nájera; Munilla, con 265, o Laguna con 207, más que Murillo de río Leza). Pero, como veremos, en ellas fue donde el hambre de tierras se manifestó con más claridad en los años setenta, en la aplicación de los decretos de Godoy y en las desamortizaciones concejiles durante la guerra de la independencia.

Para entender estos resultados hay que tener en cuenta que la superficie cultivada era en el valle, en proporción, menor que la inculta. En Castilla ${ }^{10}$ era de un 49,8\%, pero en los pueblos riojanos analizados hasta el momento, no llega a esta cifra. En Cenicero, por ejemplo, suponía un $47,2 \%$, pero si suprimimos los llecos que los propietarios más ricos podían permitirse no cultivar, sólo alcanza el cultivo un $40 \%$. En la sierra, la tierra de cultivo se aprovechaba más y estaba más repartida. Los ganaderos trashumantes concentraban sus intereses en los pastos de veranadero y chocaban menos con los derechos de los agricultores, puesto que los rastrojos y los barbechos no planteaban los inconvenientes para el pasto que tenía la viña, aquí inexistente al sur de Leza de río Leza. Además, el ganado abonaba la tierra en el pasturaje y en la estabulación, lo que hacía aumentar la disponibilidad de estiércol y que los rendimientos fueran incluso superiores a los del valle, a pesar de las condiciones geográficas y climáticas. Incluso los más pobres podían allegar estiércol «echando paja, hojas de árboles y ulaga en los caminos donde se junta el agua, y se curan amontonándolas con horquillos» ${ }^{11} \mathrm{y}$ aprovechando los excrementos dejados por el ganado en los caminos. Así, son explicables los rendimientos del 
trigo hasta de 1 a 6 en Ajamil o de la cebada de 1 a 8 y de 1 a 7 en Ajamil y Soto, respectivamente, en tierras de primera calidad de secano ${ }^{12}$.

La producción cerealera cuantificada por los diezmos es menor que la de Murillo de río Leza, un pueblo en el que la superficie cultivada es muy elevada, pero, como puede verse, mucho mayor que la de Cenicero, en donde el vino es el producto predominante ${ }^{13}$.

$\begin{array}{cll}\text { vecinos } & \begin{array}{l}\text { Diezmo } \\ \text { en 1752 }\end{array} & \begin{array}{l}\text { Media del } \\ \text { (media 1750-59) }\end{array}\end{array}$

$\begin{array}{lrll}\text { Jalón* } & 39 & 111,7 \text { fan } & 2,8 \text { fan } \\ \text { Ajamil } & 64 & 144,8 » & 2,2 » \\ \text { Muro } & 104 & 267,6 » & 2,5 » \\ \text { San Román } & 136 & 266,4 » & 1,9 » \\ \text { Cabezón } & 50 & 101,6 » & 2,0 » \\ \text { Murillo } & 191 & 743,9 » & 4,1 » \\ \text { Cenicero } & 250 & 250 » & 1,0 »\end{array}$

En muchas localidades de la sierra es probable que se llegara a la autosuficiencia o a necesidades de importación de cereal que, en todo caso, son inferiores a las constantes de Cenicero. Hay datos de importaciones por los concejos en los años de 1794 y 1795 o en la crisis de principios de siglo, pero junto a ello, encontramos manifestaciones sorprendentemente contradictorias. En Laguna de Cameros, los vecinos dicen no querer el trigo prestado por el arca de misericordia, a pesar de que los préstamos se hacían sin interés: en 1752, el visitador del obispado de Calahorra dice que el trigo no se ha distribuido «a causa de no necesitarlo los vecinos»; en 1761, «habiendo citado una dos y tres veces a los pobres de esta villa para el que recurriere por él» nadie se presentó. En 1766, el párroco ha de repartir el trigo entre cinco o seis vecinos y, asombrado, dice: «tengo bastante experimentado que más quieren buscarlo por otra parte, aunque sea prestado, que llevarle de dicha arca, la que aquí nada sirve ni servirá a no mudar totalmente la gente de genio». Al año siguiente, ante la misma situación, añade: «y juzgo harán siempre lo mismo». Al fin, en 1784, venden el trigo del arca «por no pedirlo ni necesitarlo los vecinos labradores»- e imponen el capital obtenido en la Compañía de Longistas de Madrid al 3\%. Su producto anual irá destinado a limosnas para pobres ${ }^{14}$.

Desde luego que estas manifestaciones no permiten pensar en una situación idílica. Pobres y labradores había y así lo demuestran los repartos del dinero proveniente de los réditos del capital invertido y los que otra «obra pía de pobres» destinaba tradicionalmente a limosnas. (Véase el gráfico 11). Tampoco es posible aducir que en plena dedicación ganadera los présta-

* Media de 1770-79 del diezmo de trigo.

10. Cfr. ORTEGA, M., La lucha por la tierra en la Corona de Castilla, Madrid, 1986; DONEZAR, J., Riqueza y propiedad en la Castilla del Antiguo Régimen. La provincia de Toledo en el siglo XVIII. Madrid, 1984, y GARCÍA SANZ, A., Desarrollo y crisis..., espec. p. 127 y ss.

11. AHDLo. (Archivo Histórico Diocesano de Logroño), Cabezón, 1770, leg. 7, Interrogatorio para el catastro...

12. AHPLo. Sec. Catastro, respuestas generales.

13. AHDLo. Cajas ordenadas por pueblos, legs. correspondientes a tazmias.

14. $I b$., Leg. 9, Libro del Arca de Misericordia, 1673-1828. 
mos de trigo no fueran utilizables, porque en Laguna, aunque con dificultades extremas para la agricultura, había 2.400 fanegas cultivables, el 32,4\% del término. La facilidad con que desde mediados de siglo se están descapitalizando las arcas de misericordia -generalmente para emplear su capital en reparaciones de las iglesias- en varias localidades estudiadas ${ }^{15}$ es un síntoma que habrá que explicar. Puedo adelantar que, salvo en períodos de malas cosechas, los préstamos se devuelven con normalidad y los déficits se subsanan rápidamente.

Salvo en los períodos críticos, con malas cosechas generales -principios de los noventa, pero sobre todo la década primera del XIX- la producción de trigo fue al alza en Jalón, San Román y Cabezón, se mantuvo en Muro y decayó en Ajamil. Pero, en proporción con la población, a la baja desde mediados de siglo, puede afirmarse que prácticamente todas las localidades vieron aumentar sus recursos cerealeros. En algunas, como Muro, si la producción de trigo se mantuvo hasta la primera década del XIX, la de otros cereales -cebada y centenoincluso creció, como es habitual en las zonas con complemento ganadero estante amplio ${ }^{15 \mathrm{bis}}$ Con menos intensidad, el proceso puede verse en otras localidades (vid. gráficos de producción en apéndice, 1 a 7 ).

\section{Diezmo de trigo (Medias por décadas, en fanegas) ${ }^{16}$}

\section{Local. de la sierra:}

$1750-59 \quad 1760-69$

Jalón

Ajamil

Muro

San Román

Cabezón

$\begin{array}{rrrrrc} & 85,4 & 111,7 & 148,0 & 125,3 & 120,9 \\ 144,8 & 92,7 & 70,9 & 68,8 & 70,8 & 76,1 \\ 267,6 & 251,4 & & & 255,3 & 229 \\ 266,4 & 225,9 & 254,2 & 341,0 & & 269,3 \\ & 101,6 & 118,3 & 141,7 & 131,6 & 102,8\end{array}$

Local. del valle:

$\begin{array}{llcccc}\text { Murillo } & 743,9 & 651,3 & 661 & 623,4 & \\ \text { Cenicero } & 250 & 185 & 192 & 180 & 190\end{array}$

Nótese que en las dos localidades del valle la producción fue a la baja; además la población creció. De las dos localidades riojanas propuestas, la más dedicada al vino y la que más redujo su producción de trigo, Cenicero, tuvo el crecimiento más vigoroso: de unos 1.000

15. El contraste de la descapitalización de las arcas de misericordia con el desarrollo de los pósitos que, según Anes, aumentan su «capitales» en trigo a más del doble en la 2. ${ }^{a}$ mitad del XVIII, sólo se puede explicar por la evolución que sufre el sector benéfico religioso ante la introducción de nuevas vías de previsión afectas a la asunción por instituciones civiles -municipios, sociedades económicas, montepíos- de algunas ocupaciones desarrolladas tradicionalmente por la iglesia. Sobre este punto hay referencias en mi tesis, que, con el título «La crisis de la beneficencia aragonesa al final del Antiguo Régimen», se publicará próximamente. Cfr. tam. ANES, G., «Los pósitos en la España del siglo XVIII», Economía e ilustración, Barcelona, 1969.

15 bis. GARCÍA SANZ, A., Desarrollo y crisis... especialmente, p. 130.

16. AHDLo., Tazmías. 
habitantes a mediados de siglo pasó a más de 1.500 al final y a 2.000 en la década de los veinte del XIX. Mientras, las localidades cameranas viejas descendían drásticamente ${ }^{17}$ :

\section{Población en vecinos}

\begin{tabular}{|c|c|c|c|c|c|}
\hline \multirow{3}{*}{ 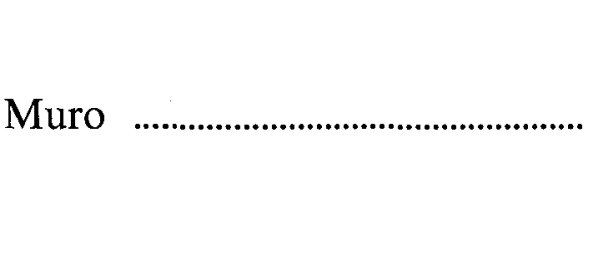 } & 1752 & 1775 & 1799 & & \\
\hline & 104 & 82 & 71 & & \\
\hline & 1752 & 1770 & & 1806 & 1818 \\
\hline Cabezón ........................................................ & 50 & 30 & & 30,5 & 33,5 \\
\hline
\end{tabular}

Así pues, mientras la población serrana descendía, los recursos cerealeros tendían a mantenerse o a crecer, más todavía en proporción al número de pobladores. La dedicación, tanto de tierras como de hombres, a la actividad agrícola hubo de crecer proporcionalmente, como lo demuestran las cifras de diezmantes en aquellas localidades donde se han podido obtener -vid. gráficos 1 a 4 en apéndice- o los procesos roturadores producidos en el Camero Viejo en paralelismo a los observados en el valle. Los misérrimos bancales en las laderas -apreciables todavía en Munilla, Enciso, Soto- son pruebas de hasta dónde llegaron la sed de tierras y los intentos de contrarrestar la crisis. Como ha dicho García Sanz, conforme «subían los precios de los productos agrícolas empezaba a ser económicamente viable el cultivo de un mayor número de tierras con un grado de marginalidad creciente» ${ }^{18}$.

Las protestas de los ganaderos contra las roturaciones se producen en el Camero en fechas idénticas a las constatadas en Cenicero o Murillo. En 1771, los regidores de Enciso, Poyales, Navalsanz, Garranzo, Villar y La Escurquilla, con el apoyo de la Mesta, protestan porque «de poco tiempo a esta parte diferentes vecinos de ella, de hecho y contra derecho, han roto y rompen, reduciendo a labor para sembrar varias porciones de tierra que siempre fueron de pastos». Los concejos habían prohibido las roturaciones, pero ha sido en vano ${ }^{19}$.

En Cabezón, el propio concejo decide vender algunas tierras que dedicaba a arriendo de pastos, contra las protestas de ganaderos de localidades vecinas -Jalón, Rabanera, Laguna y San Román- porque va contra los derechos tradicionales de comunales y «por razón de los abrevaderos de que carecen (las otras villas) en el tiempo en que benefician las lanas en el lavade ro de Ajamil». Todavía es más significativo que D. Juan Manuel Crespo, uno de los más ricos ganaderos del Camero Viejo -12.000 ovejas en 1752- haya practicado roturaciones en el territorio campanil de Jalón, entre 1782 y 1784 , y pleitee con el cabildo por esta razón ${ }^{20}$.

17. Sobre los datos de Murillo y Cenicero, la misma procedencia citada. Los diezmos de Cenicero se han extraído del tercio pagado a la iglesia de Sto. Domingo de la Calzada, mediante el simple cálculo aritmético y el aumento de los gastos de repartimiento. Sobre las cifras de Cameros, AHDLo, Tazmías y repartimientos vecinales, en legs. correspondientes a las localidades citadas.

18. GARCIA SANZ, A., Desarrollo y crisis..., p. 286.

19. AHPLo., García Sancho, 1771 , f. 20.

20. Ib., Gaona, 1770, f. 11. Tam. mi artículo, «La Rioja y Cameros: del equilibrio a la crisis», Andalán, n.o espec. dedicado a La Rioja, set. 1986. Sobre las causas institucionales de las roturaciones, GARCIA SANZ, A., Desarrollo y crisis, p. 146 y ss. 
Los procesos desamortizadores se emprendieron igual que en el valle. Aprovechando los decretos de Godoy de 1798 y la instrucción de enero de 1799, se vendieron en San Román unas cuarenta parcelas, entre 1799 y 1803, la mayoría pertenecientes a la ermita de San Pedro. No constituían una gran extensión -la mayoría eran herranes de media fanega o poco más; sólo dos parcelas tenían más de dos fanegas-, pero es importante constatar que la tasación hecha por los peritos fue superada ampliamente en el remate, en todos los casos. El alto precio sería el culpable de que todas las propiedades pasaran a manos de dos compradores únicamente ${ }^{21}$.

\section{VENTAS DE TIERRAS EN SAN ROMAN (1799-1803)}

\begin{tabular}{|c|c|c|}
\hline Extensión (celemines) & tasación (rs) & remate ( $\mathrm{rs}$ \\
\hline año 1799 & & \\
\hline 24 & 912 & 1.512 \\
\hline 5 & 1.100 & 2.320 \\
\hline
\end{tabular}

año 1801

148 cel. ( 25 heredades

más 4 vendidas en 1803 )

10.588

año 1803

33

12

6

10

4

2

7

5

2

7

6

9

6
5.506

324

132

290

120

66

210

150

80

222

234

333

216
8.601

1.282

620

400

170

120

450

170

121

550

620

420

400

21. AHPLo., Gaona, Leg. 7161, f. 59 y ss. 
SOTO DE CAMERO VIEJO

1795-1840
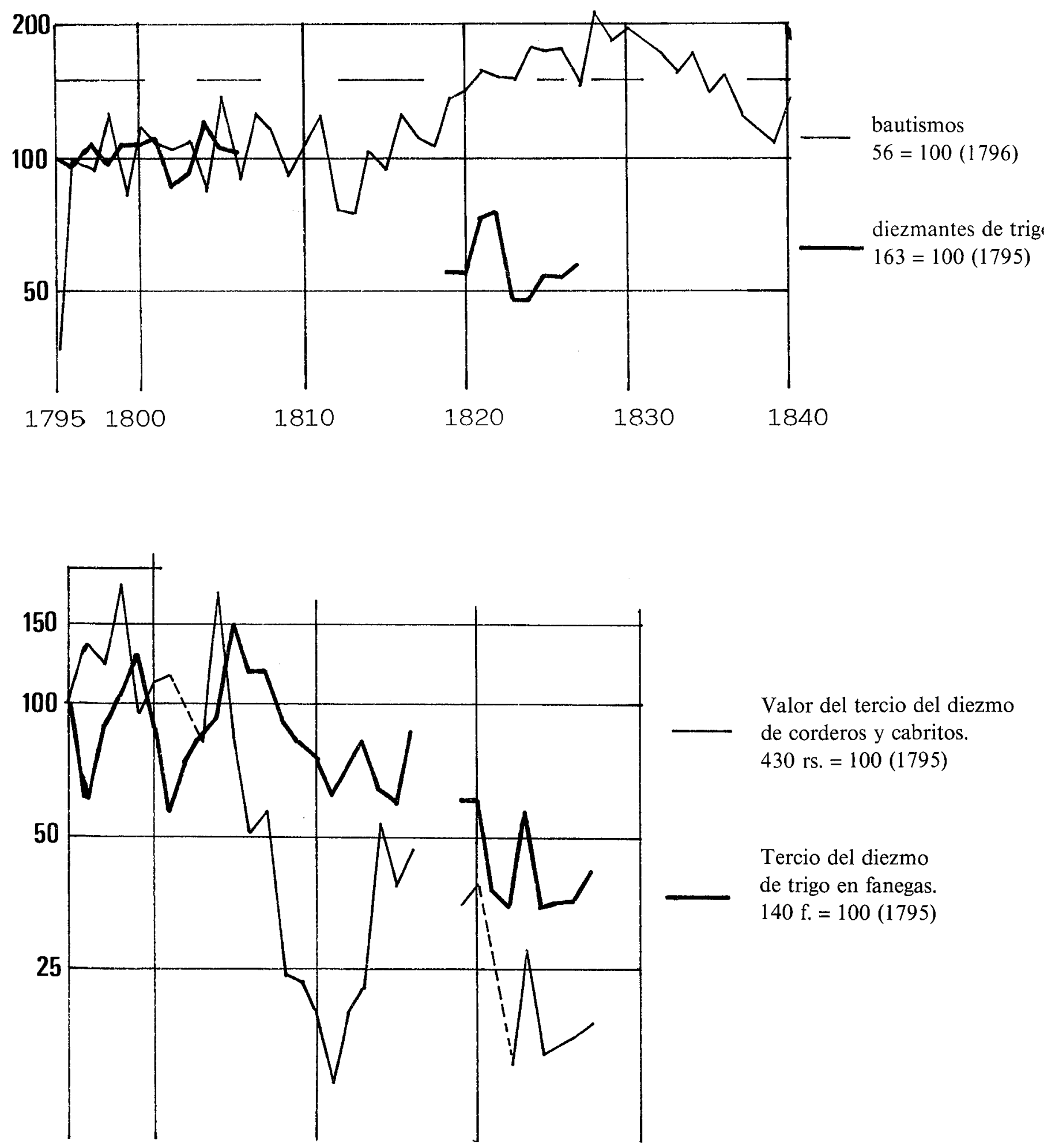

Valor del tercio del diezmo de corderos y cabritos. 430 rs. $=100(1795)$

Tercio del diezmo de trigo en fanegas. $140 \mathrm{f} .=100(1795)$ 
Los procesos desamortizadores y las roturaciones continuaron en la guerra de la Independencia y en fechas posteriores. En el valle de Ocón, la iglesia de El Redal vendió unas 25 fanegas de tierra blanca y algunos olivares en febrero de 1812. Aquí, los compradores fueron 13 y el remate estuvo siempre por debajo de la tasación. De los 11.256 reales en que se tasó el total de la propiedad a enajenar, sólo se obtuvo en el remate $9.900^{22}$. En Soto, el proceso todavía no está bien documentado, pero poseemos datos sobre roturaciones denunciadas en 1828, seguramente iniciadas en la guerra y sobre la estructura social y económica generada por la crisis ganadera y textil en la que se producen. Sobre ello sólo voy a adelantar algunos resultados seriados con el fin de que pueda apreciarse el potencial conflictivo de una localidad en la que, a pesar del descenso de los recursos básicos y de la actividad textil, la población aumentó como puede verse en los gráficos siguientes. (No obstante, el caso de Soto es una excepción, cuyo estudio se emprenderá en una futura monografía cuando lo permita la ordenación de las fuentes municipales y parroquiales).

Los roturos denunciados en 1828 por D. Marcos Elías, alcalde de la cuadrilla de Soto, se habían practicado por una veintena de labradores en numerosos términos del pueblo en una extensión total de al menos 26,5 fanegas, distribuidas en parcelas muy pequeñas. Los cuadrilleros querían reducir las tierras a pastos, a pesar de que el ganado se había reducido unas 2.200 cabezas; pero, ya no había de trashumo (a mediados del XVIII había 4.540 estantes y sólo 709 trashumantes) $\mathrm{y}$, por tanto, la presión ganadera estante aumentaba. También esgrimían la necesidad de mantener las tierras erias para surtir a la industria textil y a las necesidades domésticas de «estepas» y leña. Los roturantes decían estar «constituidos en la mayor miseria por la decadencia de la fábrica de paños», mientras cifraban sus expectativas de subsistencia en la agricultura, para lo que roturaban pasadas, «descansos», etc. ${ }^{23}$

En definitiva, roturaciones y mantenimiento, cuando no crecimiento, de la producción cerealera, proporcionalmente al número de pobladores, son algunos de los factores a tener en cuenta a la hora de explicar el papel de amortiguador la agricultura en el Camero Viejo, e incluso, en aquellas localidades en las que la industria textil era escasa o había decaído antes, el orden preferente, el valor social que tenía la dedicación agraria en las economías locales. Como vamos a ver, en éstas, la ganadería, por la estructura de propiedad que generó en el Camero oriental, no era desde mediados del XVIII sino un complemento de la renta agraria de las familias pobres, obtenido por medio del trabajo asalariado de los miembros más jóvenes -pastoreo para los hombres, labores textiles para las mujeres y los niños-, mientras proporcionaba a los grandes propietarios el capital que, invertido fuera de Cameros mientras duró el proceso de pérdida de rentabilidad de la ganadería, privaría a las sierras de los medios necesarios para sumarse a la vía de las transformaciones capitalistas que tenía lugar en regiones, donde el desarrollo agrario y la infraestructura comercial resultaban más prometedoras para la burguesía.

\section{Propiedad ganadera y descapitalización}

Los únicos productos con capacidad de monetarizar la economía del Camero Viejo -los derivados de la ganadería- habían constituido a los grandes propietarios de ganado en una élite

22. Ib. Sec. Municipios. El Redal, leg. 4/15. tazmías.

23. Ib., sec. Judicial, caja 280. Los datos de los gráficos, del AHDLo., Soto, Libros de bautismos y 
muy distanciada por su poder económico del resto de cameranos obligados a sumar rentas, de diversa procedencia, pero obtenidas del trabajo o de una precaria propiedad agraria. Los privilegios que la Mesta sumaba a su condición, en la mayor parte de hidalgos o de eclesiásticos -muchos de ellos naturales de las localidades cameranas mismas, segundones de las grandes familias- los elevaba a una categoría de «aristocracia local». Gobernaban los concejos, por sí mismos o por sus parciales, y desde ellos influían decisivamente en el arrendamiento de pastos de verano para sus rebaños. Para facilitarlo, podían llegar a cambiar de vecindad, ellos mismos -aprovechando la vecindad de la esposa, entre otros sistemas- o alguno de sus familiares. Hay sobre esto quejas continuadas. En Santa María, por ejemplo, «se ha experimentado que D. Juan de Albalillos y D. Martín Sáenz de Tejada, sujetos muy acaudalados, y de pocos años a esta parte avecindados en la dha. de Viguera -que tenía comunidad de pastos en varias localidades, entre ellas Santa María- no sólo se aprovechan de todos los pastos comunes con sus rebaños lanares que han comprado y consumen los pastos privando de este modo a los ganaderos de menores proporciones...». Además, «rompen el trilladero, se comen las yerbas precisas y necesarias para los ganados de labor ${ }^{24}$.

Aunque no se intentarán definir aquí en extensión los factores estructurales en que se asienta esta clase social privilegiada, es necesario adelantar que todo el Camero Viejo es de señorío, la mayor parte del conde Aguilar, pero también de diferentes casas u órdenes religiosas como las Bernardas de Herce, el monasterio de San Prudencio, etc., y que además existen otras restricciones territoriales como, por ejemplo, las Hermandades o los solares (Tejada y Valdeosera). La presión de estos solares hidalgos sobre las localidades propias y cercanas es enorme. La Junta General del Solar de Valdeosera es «dueña privativa de Valdeosera y de toda su jurisdicción». Mantiene acotado el borreguil e impide el pasto de los ganaderos extraños al solar -con lo que constantemente hay litigios con Terroba- y cultiva el término y cuida los pastos por medio de «colonos renteros» ${ }^{25}$.

En muchos pueblos, los componentes del estado general no se contentaron con los interminables pleitos que las corruptelas del estado noble les hacía interponer. En Enciso, por ejemplo, las irregularidades en las cuentas municipales que habían cometido D. Francisco Antonio Ruiz de Gordejuela y D. Félix López de Murillas, alcalde y regidor por el estado noble en 1766, fueron el pretexto, entre otros, para que se produjera un tumulto. Los dos hidalgos, que, facultados por una ejecutoria ganada en el siglo XVII por el estado noble, manejaban la mitad de los oficios honoríficos del concejo -sólo tres componían el estado noble de Enciso-, vieron que el estado general quería «arrogarse el manejo de ellos» y que para ello «conmovieron a los más vecinos (...) de que resultó amotinarsen y tumultuarsen quasi todo el pueblo, profiriendo palabras graves, feas y denigratorias contra mí y demás hijosdalgo, diciendo entre otras que eramos unos usurpadores y estafadores de la república...». Gordejuela tuvo que encerrarse en casa, «temoroso de que atropellasen mi persona y la jurisdicción que ejercía», según él mismo hubo de decir en el pleito que siguió. A éste, los del estado general llevaron documentación sobre varios agravios, entre ellos el de la actuación fraudulenta: «... desde que tomaron la posesión, aun con más especialidad el referido Gordejuela, han exigido varias cantida des que componen crecidas sumas de diferentes vecinos extrajudicialmente con el colorido de multas y penas pecuniarias que se han apropiado a su bolsillo y para sus propios usos». Con estas sumas, Gordejuela «ha tenido lo necesario para mucha parte de su manutención y ornato, como para la de su mujer y su familia»; y «a expensas de la villa» ha seguido pleito con

24. AHPLo., Gaona, 1773, f. 28.

25. Ib., Gaona, 1762, f. 34. Sobre la situación de los colonos, Gaona, 1776, f. 57. 
un vecino en Valladolid, adonde se trasladó para seguirlo, en unión de un cura de Enciso, con el fin de despojarle de una herencia.

El pleito contra el estado noble terminó con prisión para algunos alborotadores y con la exculpación, con fianza, de Gordejuela, a quien en Valladolid se le reconoce como «pobre» en la sentencia dada en 1768. Tanto los dos hidalgos, como D. Antón Cabezón, el otro que compone el estado noble, volverán a ocupar puestos en el concejo, a pesar de que la oposición del estado general continuó. En 1774, Gordejuela volvió a ser contestado, pero pudo esgrimir que de los delitos que le imputaban «por sentencia de la superioridad, he sido absuelto». En 1776, D. Antón Cabezón dice que «se quita del oficio» por su edad, pero, el año siguiente, vuelve a ser alcalde, mientras Gordejuela y Murillas ocupan dos regidurías ${ }^{26}$.

El caso de Enciso es un ejemplo de la pervivencia de los privilegios que mantenían el usufructo de la administración local en manos de los hidalgos. El sistema de elección de alcalde por el detentador del señorío entre dos propuestos por el concejo, el reparto o la alternancia de los cargos entre los dos estados y otros usos generalizados eran privilegios a los que los ricos ganaderos sumaban los obtenidos de la Mesta para poder mantener sus rebaños. A ello hay que sumar el auxilio del clero camerano, compuesto por segundones de las casas hidalgas, y detentador por ello de gran parte de la cabaña trashumante.

En Montalbo, Leza y Torre, los curas poseen a mediados del XVIII más de la mitad del ganado lanar; en Clavijo, Trevijano y Santa María, más del $40 \%$.

\section{GANADO LANAR EN PROPIEDAD DE ECLESIASTICOS ${ }^{27}$}

\section{JURISDICCIONES}

Lagunilla

Ribafrecha

Clavijo

Robres

Leza

Trevijano

Zarzosa

San Román

Luezas

Terroba

Montalvo

Santa María

Torre

Jalón

Muro

Cabezón

Rabanera

Ajamil*

\section{TOTAL \\ CABEZAS}
4.700
2.610
2.196
3.372
1.049
1.500
9.833
2.028
881
932
847
1.123
3.289
692
3.497
1.481
3.152
$\underline{12.253}$

55.435

\section{TOTAL PROP. ECLESIAST.}

\begin{tabular}{rr}
620 & 13,2 \\
370 & 14,1 \\
1.078 & 49,0 \\
357 & 10,5 \\
686 & 65,3 \\
600 & 40,0 \\
3.210 & 32,8 \\
740 & 36,4 \\
142 & 16,1 \\
124 & 13,3 \\
690 & 814 \\
550 & 48,9 \\
1.869 & 56,8 \\
108 & 15,6 \\
923 & 26,3 \\
315 & 21,2 \\
332 & 10,5 \\
261 & 2,1 \\
\hline 12.975 & 23,4
\end{tabular}

*. Excluyendo la propiedad de Juan Crespo, 11.445 cabezas, el porcentaje de prop. de eclesiásticos es 29,4. Así, sin contar la prop. de Crespo, el total de cabezas sería de 43.990 .

26. $I b$., García Sancho, 1767 , ff. 67 y ss.; 1768 , ff. 37 y $60 ; 1774$, ff. 8 y 74; 1776, f. 38 .

27. AHPLo., Ib., sec. Catastro, respuestas generales. 
En Torre, Lagunilla, Hornillos o Zarzosa, más de la mitad del ganado está concentrado en rebaños de más de 300 ovejas que son propiedad de entre 3 y 9 ganaderos. Una cata de norte a sur nos permite comprobar que, salvo la excepción más notable de Larriba-Torremuña, la concentración se va haciendo superior, igual que la presión ganadera sobre la superficie y sobre el vecindario, a medida que se avanza hacia el sur y se gana altura. Los pueblos más altos que Soto son los que tienen mayor proporción de ganado, y los que mantienen la trashumancia hasta el punto de reducir el estante a poco más que la cabrada de la villa y el rebaño de abasto de la carnicería. Son, asimismo, los que soportan una mayor concentración de la propiedad, aunque ésta sólo llegue al máximo en los pueblos más altos como Laguna, Zarzosa o Ajamil. Juan Manuel Crespo que tiene en Ajamil 12.000 ovejas, casi el total de lanar del pueblo, es con mucho el mayor propietario de las localidades estudiadas. (Vid. gráficos 8 a 10 y cuadro). 
1752. DISTRIBUCION DE PROPIETARIOS POR NUMERO DE CABEZAS

\begin{tabular}{|c|c|c|c|c|c|c|c|c|c|c|}
\hline \multirow{2}{*}{ JURISDICC. } & \multicolumn{2}{|c|}{$0-50$} & \multicolumn{2}{|c|}{$51-150$} & \multicolumn{2}{|c|}{$151-300$} & \multicolumn{2}{|c|}{$300-\ldots$} & \multirow{2}{*}{\multicolumn{2}{|c|}{ tot. cab.s tot. propt.s }} \\
\hline & propt.s & \% cab.s & propt.s & $\%$ cab.s & propt. $^{\text {s }}$ & $\%$ cab.s & propt.s $^{\mathrm{s}}$ & $\%$ cab.s & & \\
\hline Tierra Baja Ocón* & 39 & 25,0 & 16 & 42,3 & 4 & 20,5 & 1 & 11,8 & 3.824 & 60 \\
\hline Tierra Alta Ocón* & 91 & 22,5 & 28 & 32,7 & 5 & 13,6 & 5 & 31,1 & 7.439 & 129 \\
\hline Lagunilla** & - & - & 1 & 2,7 & 3 & 16,2 & 9 & 81,0 & 4.690 & 13 \\
\hline Robres* & 59 & 24,4 & 31 & 49,7 & 8 & 25,8 & - & - & 5.346 & 98 \\
\hline Ribafrecha** & 1 & 1,9 & 5 & 18,7 & 4 & 28,3 & 3 & 50,9 & 2.610 & 13 \\
\hline Torre* & 16 & 12,5 & 9 & 25,0 & 3 & 19,1 & 1 & 43,1 & 3.485 & 29 \\
\hline Hornillos*** & 7 & 4,4 & 2 & 4,2 & 4 & 24,2 & 4 & 66,9 & 3.836 & 17 \\
\hline Larriba-Torremuña ${ }^{* * *}$ & 39 & 38,3 & 11 & 47,2 & 2 & 14,3 & - & - & 2.318 & 52 \\
\hline Zarzosa*** & 8 & 1,6 & 9 & 9,3 & 1 & 1,8 & 9 & 87,1 & 9.911 & 27 \\
\hline
\end{tabular}


Sin embargo salvo los casos localizados muy al sur, en las cercanías del collado de Sancho Leza, en el resto del Camero Viejo la propiedad, aunque en pocas manos, era mucho menor a mediados del siglo XVIII. En pueblos con poca presión ganadera, la trashumancia ya se había abandonado o se abandonaría pronto.

La reversión del conjunto de factores estructurales que había mantenido el modelo expansivo ganadero comenzó a producirse antes de que fuera afectado por los factores de coyuntura $^{28}$. Lo que la «aristocracia ganadera» pudo interpretar como una pérdida de privilegios desde 1767 respondía a la necesaria asunción por los reformistas de una política que tuviera en cuenta el ascenso poblacional, la demanda de tierras de cultivo y, sobre todo, el problema de las subsistencias y su regulación comercial. La alarma de los ganaderos cameranos ya no pararía en lo que quedaba de siglo. Las fricciones con el proceso de expansión agraria, leves en Cameros, se agudizarían en los «extremos» y en pastizales de transterminancia. En 1768, el señor de Agoncillo, D. Gerónimo de Frías, propietario de la dehesa de San Martín de Berberana, pretende impedir el uso de los pastos a los ganaderos de Enciso que tradicionalmente los utilizaban. Frías había metido 70 yeguas de vientre. Años antes, en 1760, los de Leza ya habían tenido los mismos problemas ${ }^{29}$.

Los datos que poseo sobre Extremadura son más tardíos, pero igualmente reveladores. Los Crespo, de Ajamil, en el año pasado de noventa y siete fueron atropellados por los vecinos de la villa de La Puebla a fin de labrar varias porciones de terreno de la referida dehesa (sic); al año siguiente, un vecino de Zafra les impidió el pasto en unos terrenos del convento de Santa Clara de Zafra, aunque, según José y Vicenta Crespo, éste «no tiene ni una yunta suya propia con que pueda cultivarla». En 1801, es en las cercanías del Camero Viejo, en Santa Cruz de Yanguas (Soria) donde Teresa Las Heras, en una carta al escribano Gaona, se niega enérgicamente a arrendar los pastos a los Crespo:

«... requiero una dos y tres veces y las demás en derecho necesarias a D. Josép Crespo, vecino de la villa de Ajamil y residente en la ciudad de Logroño, para que si viere le conviene busque yerbas para erbajar sus ganados finos trashumantes en el agosto del año próximo venidero de 1802, porque las yerbas de los prados que dicen del Royo Castellanos sitos en el término del lugar de Sta. Cruz que son míos propios los necesito para los míos como público y notorio» ${ }^{30}$.

Problemas parecidos hay en Rabanera. Aquí, las quejas por las pérdidas de derechos mencionan los decretos de 1767 como causantes directos y esgrimen el derecho de posesión, todavía en 1796, que, desde luego no había sido respetado ${ }^{31}$.

Este y otros factores, bien conocidos ya por diversos estudios, demuestran el proceso de ruina que sufrió la cabaña ganadera española. Con pocas variaciones y de escasa relevancia, el proceso es similar al sufrido en el Camero Viejo, y por ello no me detendré más. Sí me interesa precisar que la caída de las explotaciones ganaderas produjo entre los ganaderos del Camero Viejo un impacto diferenciado. En aquellos que mantenían después de mediados de siglo un rebaño de escasa proporción, estante y necesariamente complementario, que les obligaba a desarrollar otras actividades, el proceso fue similar al registrado en el valle (salvo en las pocas localidades donde la dificultad agrícola era extremada): se dispersó la propiedad sobre el ganado

28. Ib., Gaona, 1768, ff. 12 y 14, para Laguna y Hornillos; 1770, f. 11, para Cabezón. Cfr. GARCIA SANZ, Desarrollo y crisis, p. 294, especialmente.

29. AHPLo., García Sancho, 1768, f. 9, para Enciso; y Manuel de Sicilia, 1760, f. 3, para Leza.

30. Ib., Gaona, 1798 , f. $54 ; 1799$, f. $90 ; 1801$, f. 71 .

31. Ib., Gaona, 1796, f. 37. 
estante, mientras el trashumante en declive tendía a mantener la concentración y aumentaba el ganado de labor (véanse cuadros 1 y 2 en apéndice). Aunque, en general, pudieron mantener más alto el techo de ganado lanar y cabrío, se vieron precisados a intensificar la ocupación agrícola. Que en un pueblo como Cabezón, que ha perdido 20 vecinos entre mediados y fin de siglo, se produzca la sustitución de bueyes por mulas es verdaderamente significativo ${ }^{32}$.

$\begin{array}{ccc} & \text { mulas } & \text { bueyes } \\ 1752 & 17 & 16 \\ 1812 & 22 & 6 \\ 1818 & - & 0\end{array}$

Igualmente lo es que en Laguna, en 1804, se pida la transformación de un batán en molinero harinero. «Arruinado y desbaratado (...) por la gran decadencia que se experimenta en este pueblo en la fábrica de paños y bayetas», el batán serviría para moler grano ${ }^{33}$.

Pueden parecer meras resistencias antes de la emigración, pero no se producen mediante un cambio drástico de ocupación, sino a base de la intensificación de la que había sido la sustentadora principal de núcleos familiares en los que la movilidad de los miembros jóvenes había sido tradicional ${ }^{34}$. Cuando en 1780 , cinco maestros tejedores de San Román protestan contra una prohibición ordenancista en Soto $^{35}$, declaran que «cuasi todos sus vecinos (de San Román) son de oficio labrador y ninguno fabricante que sólo con este trato se mantenga, pues dichos vecinos labradores sólo en el tiempo muerto se valen de la industria de fabricar bayetas y algún paño para vestir sus casas», y a continuación: «sus vecinos se ocupan la mayor parte del año en las labores del campo» ${ }^{36}$. Lo que en este grupo se perdió con la crisis ganadera fueron las rentas adicionales que obtenían todos los miembros de la familia, y con ello los niveles de consumo tan altos que, según Brumont ${ }^{37}$, había en la sierra en el siglo XVI. Ciertamente, el empobrecimiento y la desmonetarización de la economía son notorios. En Cabezón, en 1806, se gastaban en la taberna 105 cántaras de vino, es decir unas tres y media por vecino, lo que resulta un consumo bajísimo. Con eso y todo, al cura del lugar le parece demasiado y, sin admitirlo, dice poder «responder de la conducta acreditada y proveza de esta vecindad ${ }^{38}$.

Sin embargo, el impacto de la regresión en los grandes propietarios ganaderos fue muy diferente. La mayor parte de ellos había acumulado una gran experiencia comercial a lo largo de las rutas de la trashumancia y disponían de verdaderos «factores», unidos casi siempre por lazos familiares, en los puntos mercantiles más importantes de Extremadura, Andalucía, Madrid e incluso América. Su movilidad les había ido despegando del «solar» hasta el punto de que algunas ordenanzas de pueblos pequeños preveían la posibilidad de que el elegido para

32. AHPLo., Sec. Catastro, respuestas generales, y AHDLo, leg. 11.

33. AHPLo., Herreros de Tejada, 1804, f. 78 y ss.

34. Cfr. los artículos citados de M. Lázaro y P. Gurrea.

35. «Se ha prohibido a los maestros de tejer para otros que fabriquen para sí, y que si fabrican para sí, no tejan para otros», cap. ${ }^{\circ} 18$ de las ordenanzas de Soto. En Gaona, 1780, f. 59.

36. $I b$.

37. BRUMONT, F., «La Rioja en el siglo XVI», ponencia presentada en el II Coloquio de Historia de La Rioja, en prensa. Tam., HUETZ DE LEMPS, A., loc. cit.

38. AHDLo., Cabezón, leg. 6. Doc. suelto, 11 de dic. de 1806. Veánse en la ob. cit. de BRUMONT, los altos consumos per cápita de vino en el siglo XVI. La reducción de éstos en el XVIII hizo variar la dirección de la colocación de excedentes vinateros de La Rioja, como ya observó HUETZ DE LEMPS. Cfr. op. cit., pp. 414-415 y figs. 101 y 102 , especialmente. 
algún cargo pudiera «tomar la determinación de quedarse a ejercer dicho su empleo o dejar sustituto a voluntad de la villa» ${ }^{39}$. En muchos casos, a lo largo de la segunda mitad del XVIII, irían fijando su vecindad fuera o alternarían su residencia en la villa natal y en otras ciudades. En el primer tercio del XIX, ya hay quejas de algunos párrocos porque los ganaderos no han traído en verano los rebaños para evitar pagar el diezmo ${ }^{40}$.

Antes de los malos tiempos, estos propietarios eran inversores en potencia, con un capital -incluido el de su rebaño- muy fácilmente movilizable. Si vendieron los rebaños, si, como dice García Sanz, tras la guerra, los rabadanes se convirtieron en propietarios, es porque ya habían encontrado otra vía de rentabilidad. Los siguientes casos, que describo en extenso, son suficientemente ilustrativos de ese «genio comercial camerano» que destacó Govantes ${ }^{41}$. Todos son de vecinos de Cabezón, un pueblo en el que la pérdida de población joven y la disminución del ganado harían pensar que se encuentra en una situación extrema de pobreza generalizada (vid. cuadro siguiente sobre población y cuadro I del apéndice para la reducción de la cabaña en algunas localidades, entre ellas Cabezón, y gráfico 3 sobre diezmos de cereales de este pueblo).

\section{CABEZON DE CAMEROS POBLACION ${ }^{42}$}

\section{HOMBRES}

$\begin{array}{ll}\text { casados } & 29 \\ \text { viudos } & 25 \\ \text { solteros }+18 \text { años } & 27 \\ \text { solteros }-18 \text { años } & 88\end{array}$

1752

1813

Diferencia

$\begin{array}{rrrr}29 & 20 & 9 & \\ 7 & 2 & 5 & \\ 25 & 1 & 24 & \text { (excl. eccos.) } \\ 27 & 17 & 10 & \\ 88 & \frac{17}{40} & 48 & \end{array}$

\section{MUJERES}

casadas

29

viudas

solteras (tot.)

Total habs.

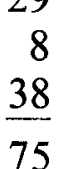

163

\section{0 \\ 7 \\ $\underline{45}$ \\ 72}

112

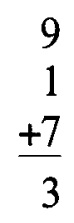

51 (excl. eccos.)

La estructura de la población en 1813 evidencia un gran deterioro: escasez de solteros y abundancia de solteras, nueve matrimonios menos que en $1752 \ldots$ Sin embargo, 7 vecinos tienen

39. Ib., Gaona, 1765, f. 23.

40. El cabildo de Laguna se queja en 1830 de que dos vecinos no pagan diezmo y primicias «a pretexto de que el primero ha dejado el suyo (rebaño) en Avila, y el segundo en un pueblo de la provincia de Extremadura, ambos a veranear». AHPLo., Herreros de Tejada, 1830, f. 76.

41. Govantes ensalzó el talento y la fidelidad de los cameranos en el comercio: «son estimados como cajeros y directores de muchas casas de comercio particulares», decía entre otras alabanzas, sin olvidar que los que sostenían todavía la población lo hacían, además de «sustituyendo otros géneros de industrias, mejorando los tejidos de lana», «aumentando la agricultura». Dicc. geográfico histórico..., art. ${ }^{\circ}$ Cameros, Madrid, 1846. 
CABEZON

Población residente en 1813

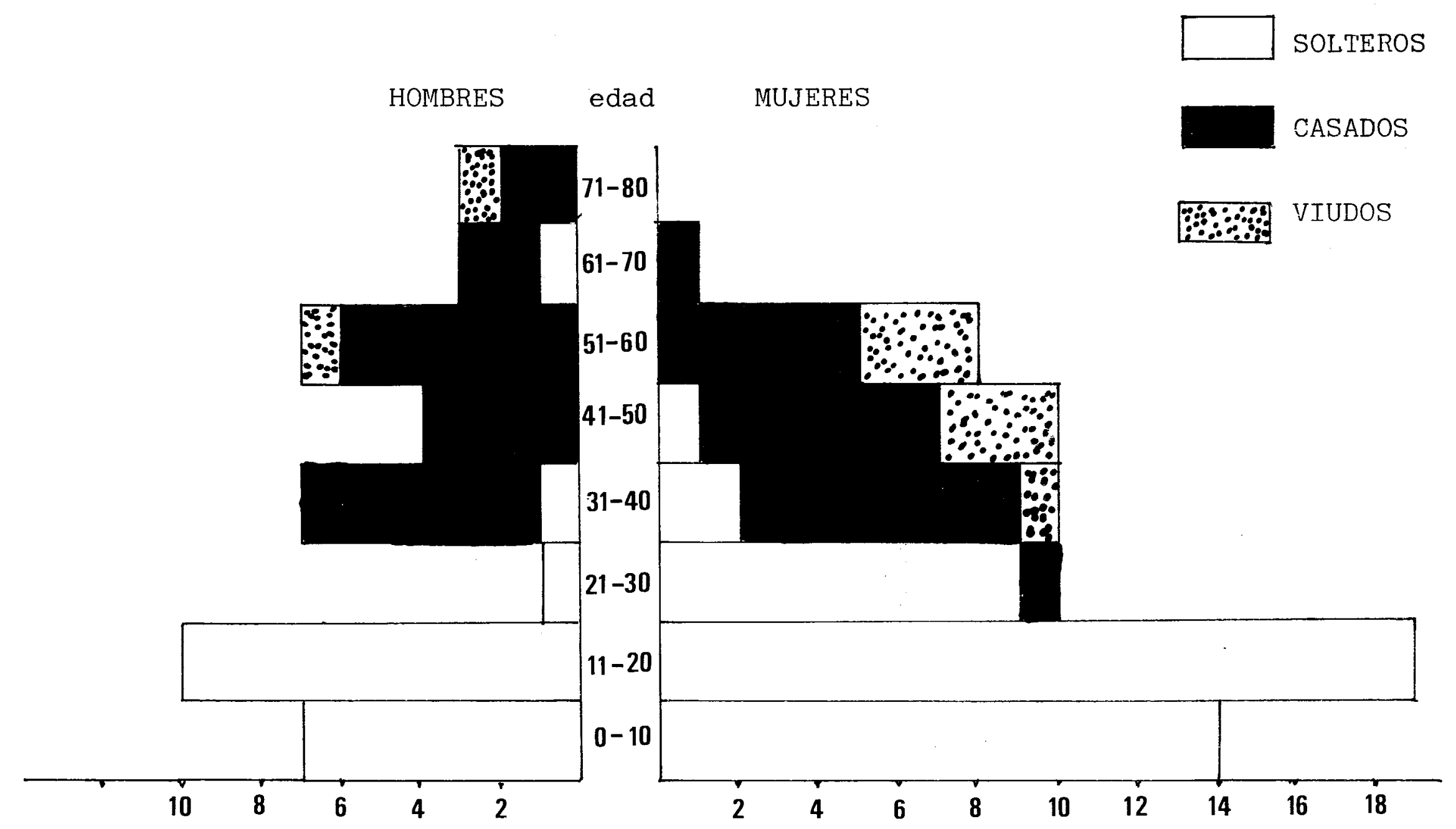


al menos una yunta de labor, y 9 poseen una caballería; todos ellos disponen además de 525 cabezas de ganado ovino. Hay cuatro declarados jornaleros, un solo pobre, que está empleado como guarda, un molinero y uno sólo que se confiesa tratante y tiene una pareja de mulas. Es claro que la actividad principal es la agricultura... pero, veamos a qué se dedican algunos vecinos unos años después.

E1 «trato» de Domingo Rodríguez «consiste (en 1821) en 10.000 reales que llevé de Soto a crédito y en 8.000 reales, importe de cobertores que compré en Palencia y paño de Ezcaray con dinero que tengo a réditos que pago por ello a un $5 \%$, y asimismo, de 8 a 10.000 reales que con el importe de lo referido vuelvo a emplear en estameñas y paños de Grazalema y Alcoy. Este año sólo ha estado cinco meses en el trato, desde San Andrés a la feria de Abril, pero tiene un «cuarto arrendado en Huelva para custodia de mis géneros», desde donde sale «a vender a San Juan de Moguer y pueblos del condado de Niebla a el por menor» y también «en el barco». Un yerno y dos hijo «que por su poca edad nada puedo confiarles» le han ayudado en el comercio. Rodríguez ha cogido durante el año 85 fanegas de cereal y sólo posee ya unas veinte reses de lanar, pero además 6 vasos de colmena y 3 mulas».

Pedro Manuel Jiménez tiene un capital de 80.000 reales y «confiesa tenerlos empleados en cobertores y estameñas para transportarlas a Cádiz donde está la mayor parte del año y en los pueblos de aquellos puertos». El escribano añade: «se ignora que negociaciones haga después».

Casimiro Fernández sólo trabaja en el trato medio año; su centro de actuación es Aracena «y pueblos de aquellas inmediaciones». Lleva 5.000 reales empleados en cobertores y paños y otros 5.000 que «saca a crédito de la villa de Soto, de la fábrica de D. Marcos Elías, y del importe de éstos podrá emplear 3.000 en algunas bayetas y estameñas del reino; a más percibe por dineros que tiene a réditos en Lebrija 24.000 reales a 5\%, 1.200 reales».

Casilda Domínguez, mujer de Manuel Martínez, dice que su marido salió a la feria de Haro el día 8 de setiembre, adonde llevó 7.000 reales «los mismos que ha empleado en mulas con las que salió el día 15 para la feria de Zafra» ${ }^{43}$.

Pero además de los tratos en la península, la vía americana, tradicionalmente utilizada para colocar excedentes textiles, constituiría en las coyunturas peninsulares más negativas una prolongación comercial, sólo dificultada por las guerras y la emancipación. Francisco Lerdo de Tejada, ya en 1826 avecindado en Cádiz, escribía a un sobrino de Muro «previniéndole que con la pérdida de las Américas, el comercio se ha arruinado y es muy remota la esperanza de que ningún muchacho haga fortuna» ${ }^{4}$. Sin embargo, con más o menos dificultad, muchos cameranos siguieron pasando a América, en la mayor parte con afanes comerciales y muchos bien protegidos por una economía familiar saneada y con muchas ramificaciones en diversas localidades andaluzas e incluso americanas. Francisco Hernández confiesa tener «bienes bastantes de fortuna» a pesar de que dos de sus hijos ya residen en Puerto Rico. Las licencias que los padres expiden ante los notarios cameranos, muy numerosas, permitiendo la emigración a los hijos contienen datos todavía no explorados sobre estas cuestiones ${ }^{45}$.

Es claro que los tintes dramáticos y sentimentalones con que, tras el descubrimiento turístico de Cameros, se pinta a los ancestros, empobrecidos tras vender su rebaño, abatidos por la despoblación, apesadumbrados por la dispersión familiar motivada por la emigración, no se compaginan con la actuación de la clase social que más facilidades encontró para dar el salto

43. AHDLo., Leg. 6, «Matrícula de ambulantes...».

44. AHPLo., Herreros de Tejada, 1826, f. 67.

45. $I b ., 1827$, f. 66 y 1828 , f. 30 . 
al capitalismo financiero, a la que, sin duda, esos sentimientos actuales motivados por la primacía concedida al terruño no les movían al incesante lacrimeo. Era mucho más negativo sufrir la falta de infraestructuras -empezando por las comunicaciones- que interfería en su actividad. Un vecino de San Román, que no había presentado a tiempo unos vales reales en la Caja de Consolidación, se quejaba de «vivir en unos pueblos tan pequeños, miserables y retirados de toda circulación (donde) no han tenido la menor noticia de las reales disposiciones comunicadas sobre el particular» ${ }^{46}$. El avecindamiento fuera, en ciudades, era indispensable para mantener las actividades comerciales y ello acarrearía la falta de inversiones en el Camero.

La disminución de los beneficios procedentes de la ganadería trashumante y la pérdida de los privilegios, que habían consolidado esa «aristocracia rural camerana», ya después de la crisis de la primera década del XIX, más del dinero que del rebaño, llegó en un momento de notable facilidad para su transformación por vías capitalistas. Sólo los que no pudieron acceder a ella desde las capas sociales más bajas se mantendrían en los pueblos cameranos con las lógicas dificultades impuestas por las consecuencias de la ausencia de inversiones y la descapitalización. Sin medios para efectuar las necesarias transformaciones ganaderas y agrícolas -algunas acometidas como la introducción de la patata poco antes de la guerra de la independencia o una nueva concentración ganadera del trashumante y una dispersión del estante (vid. sobre ello cuadro 2 en apéndice), sólo son fórmulas naturales de resistencia-, fueron constituyéndose en un mundo cerrado, atrasado y cada vez más pobre, que no pudo generar esa capa superior campesina con posibilidades de acumular capital y movilizarlo en el propio Cameros. El abandono de Cameros es antes un abandono de capitales que de hombres. 


\section{CUADRO I \\ LA CABAÑA GANADERA}

CABEZAS POR VECINO

JURISDICC.

1752

1828

1829

Hornillos

68,0

75,2

49,7

San Román

20,0

4,7

4,7

Luezas

23,2

Terroba

38,0

Montalvo

41,2

37,0

37,0

Sta. María

34,9

Torre

60,0

Jalón

26,1

19,1

39,2

18,0

26,7

Cabezón

37,0

Rabanera

62,7

16,9

16,8

Ajamil

Laguna

202,0

21,2

18,8

69,9

\section{CABEZAS POR KM²}

Hornillos

402,0

332,2

219,6

76,3

18,8

18,8

Luezas

99,0

Terroba

151,0

Montalvo

198,6

95,6

95,9

Sta. María

174,4

Torre

300,4

Jalón

121,5

77,4

255,1

66,6

98,8

Cabezón

154,3

37,7

61,5

277,3

103,8

103,1

Ajamil

$1.003,1$

83,3

73,8

346,9

FUENTES, Catastro, respt..$^{\mathrm{s}}$ generales, censo provincial 1827 e informes de GAONA, AHPLo, leg..$^{\mathrm{s}}$ de los años 1769 a 1794. 


\section{CUADRO II \\ DISTRIBUCION DE PROPIETARIOS POR NUMERO DE CABEZAS DE GANADO (TORRE Y HORNILLOS)}

TORRE (Total ganado)

$\begin{array}{ccccccc}\text { Total cabezas } & & \mathbf{0 ~ - ~ 1 0 0} & \mathbf{1 0 1}-\mathbf{3 0 0} & \mathbf{3 0 1}-\mathbf{5 0 0} & \mathbf{5 0 1}-\mathbf{1 . 0 0 0} & \text { más de } \mathbf{1 . 0 0 0} \\ & \text { años } & & & & & \\ \text { Propietarios } & 1752 & 22 & 6 & 0 & 0 & 1 \\ & 1832 & 13 & 1 & 0 & 0 & 0\end{array}$

HORNILLOS (sólo lanar trashumante)

$\begin{array}{rrrrrrr}1752 & 9 & 4 & 3 & 1 & 1 \\ \text { Propietarios } & 1828 & & & & 1 & 1 \\ & 1832 & & 1 & & 1 & 2\end{array}$

FUENTE, Catrastro, respuestas generales, y AHPLo. Gaona, Leg. años 1769-1794. 
N

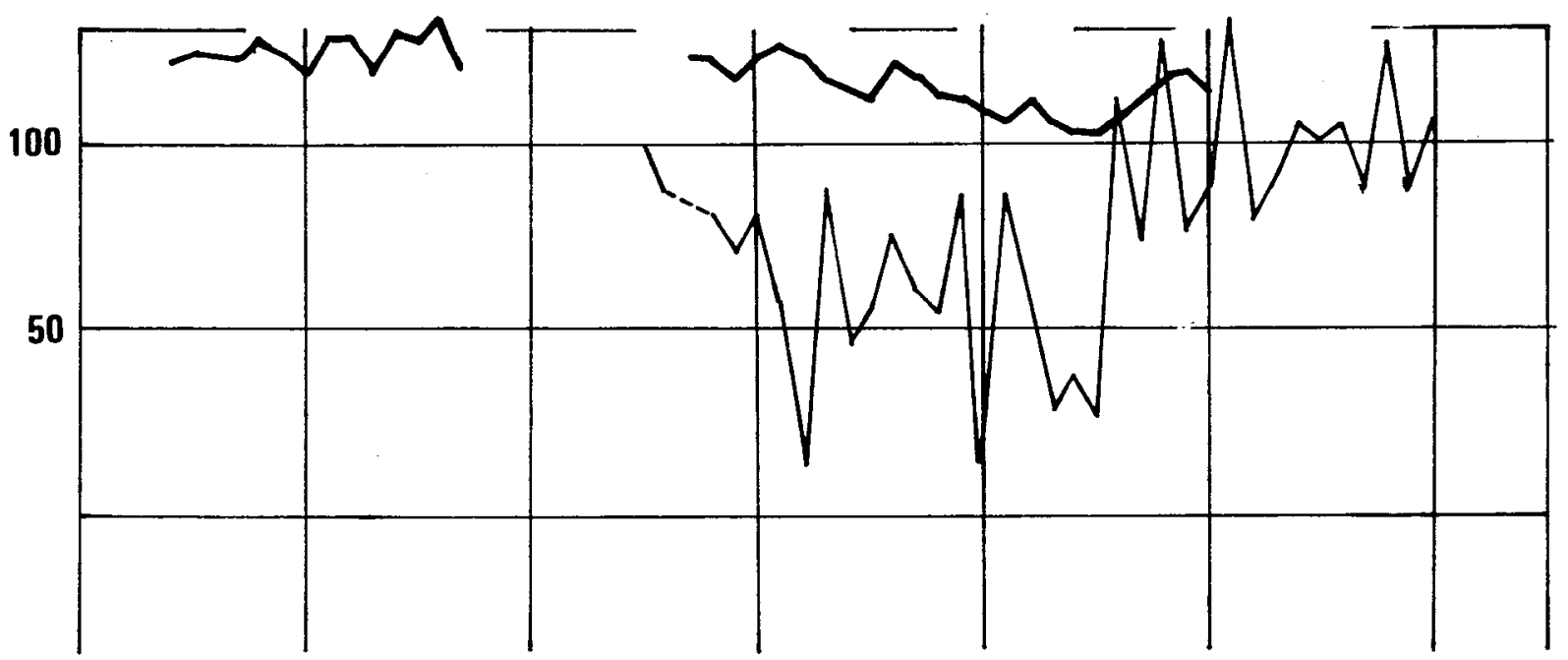

SAN ROMAN DE CAMEROS diezmos

diezmantes de trigo

$53=100(1763)$

_ bautismos

$17=100(1795)$

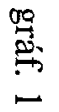

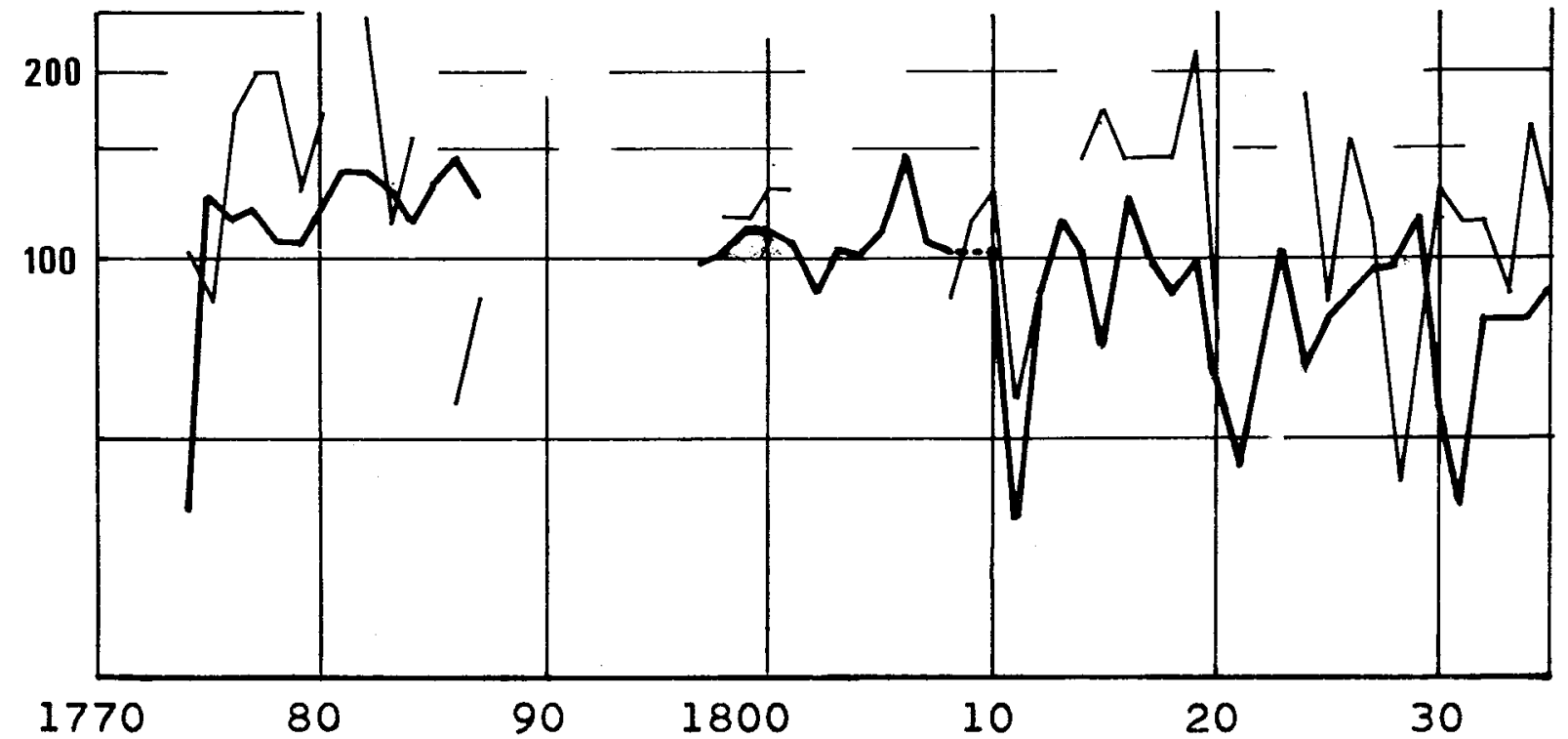

Diezmo de trigo, en fanegas $265 f=100$ (media 1774-79)

Tercio del diezmo de corderos en especie. $7=100$ (1774) 
JALON DE CAMEROS diezmos

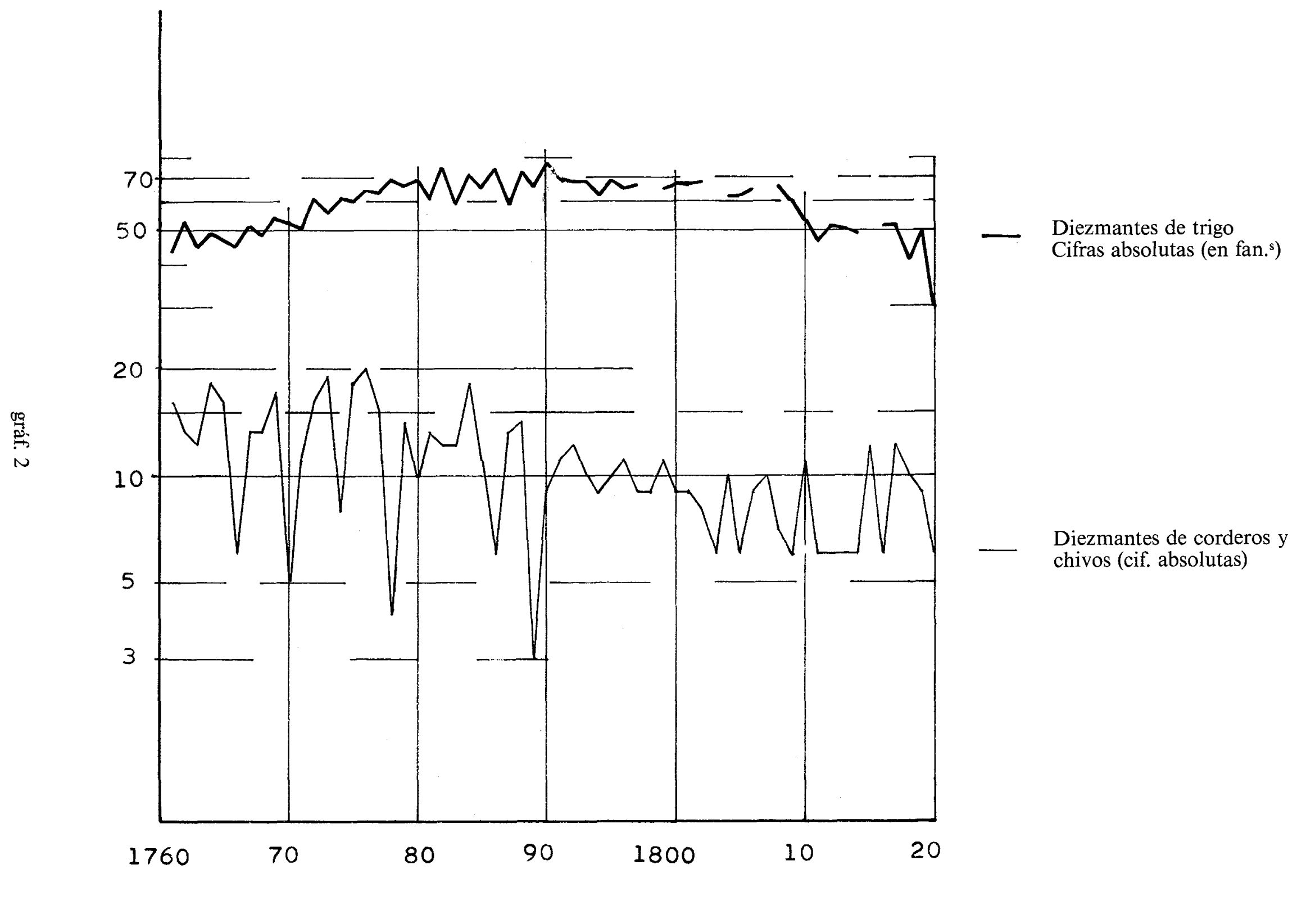




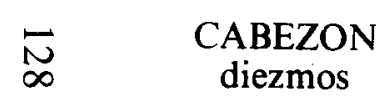

a partir del tercio

営

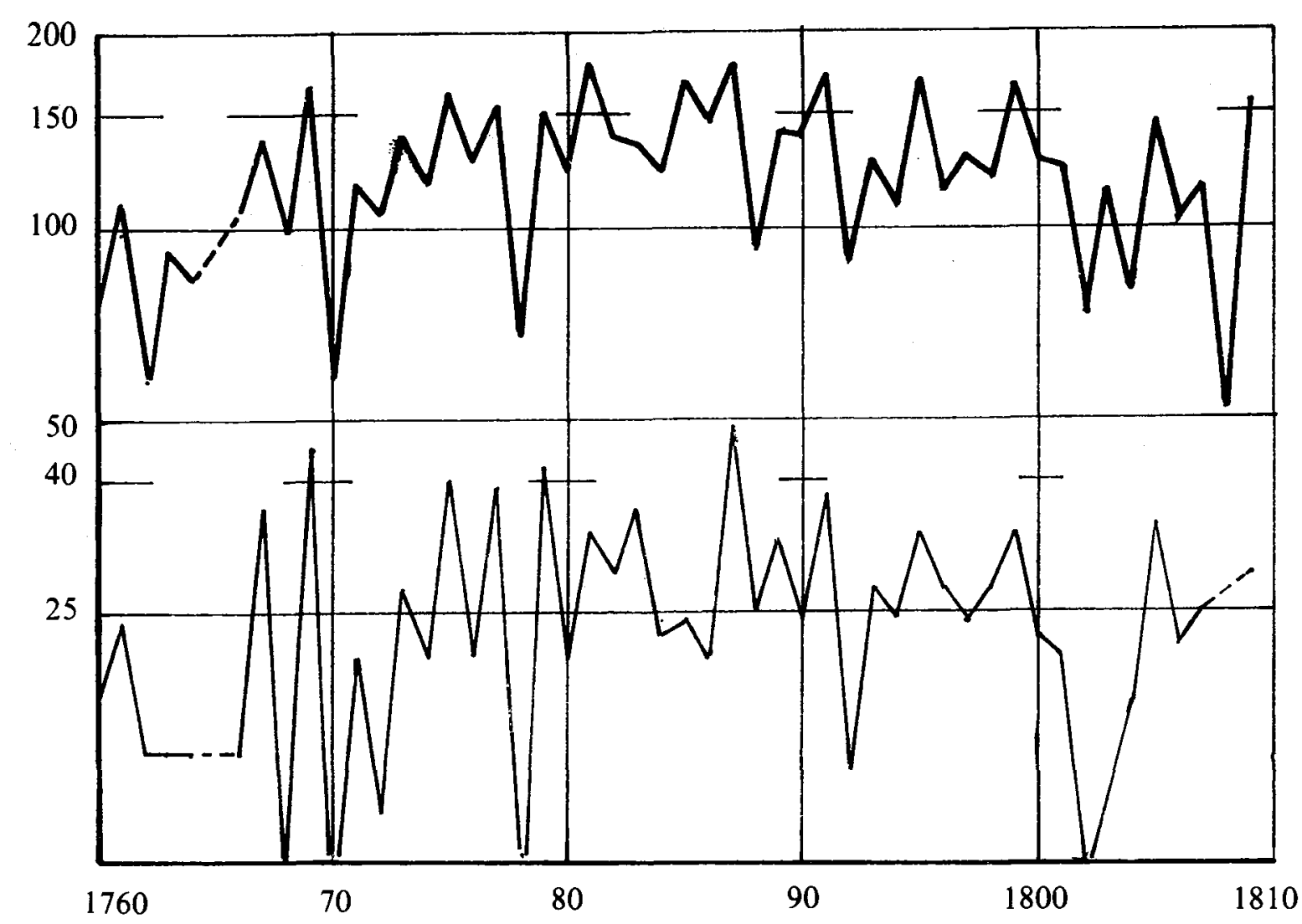

trigo en fan.s

(cif. abs.)

$\mathrm{D}=($ Tercio $\times 3)+10$

cebada en fan. ${ }^{\mathrm{s}}$

(cif. abs.)

$D=($ Tercio $\times 3)+3$

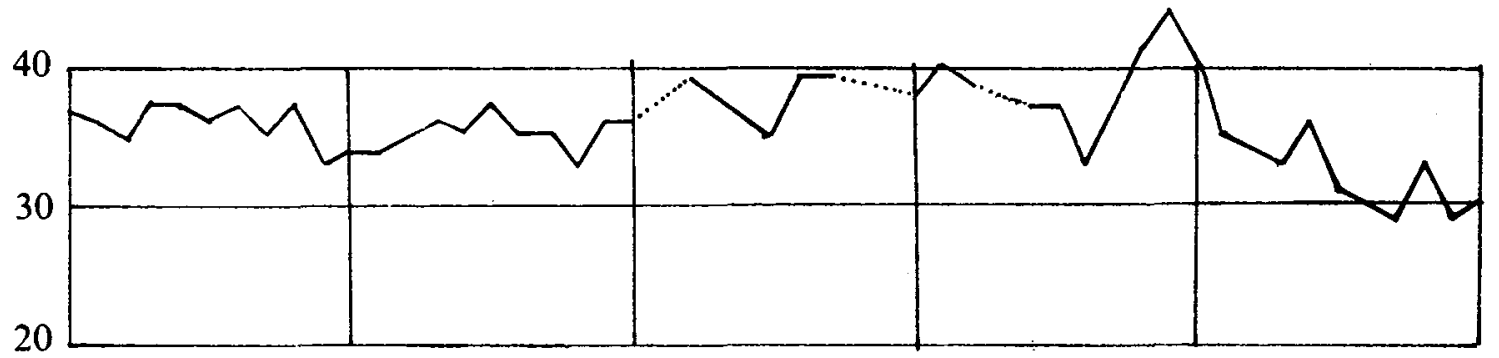

diezmantes de

trigo

(gráf. artim.a) 


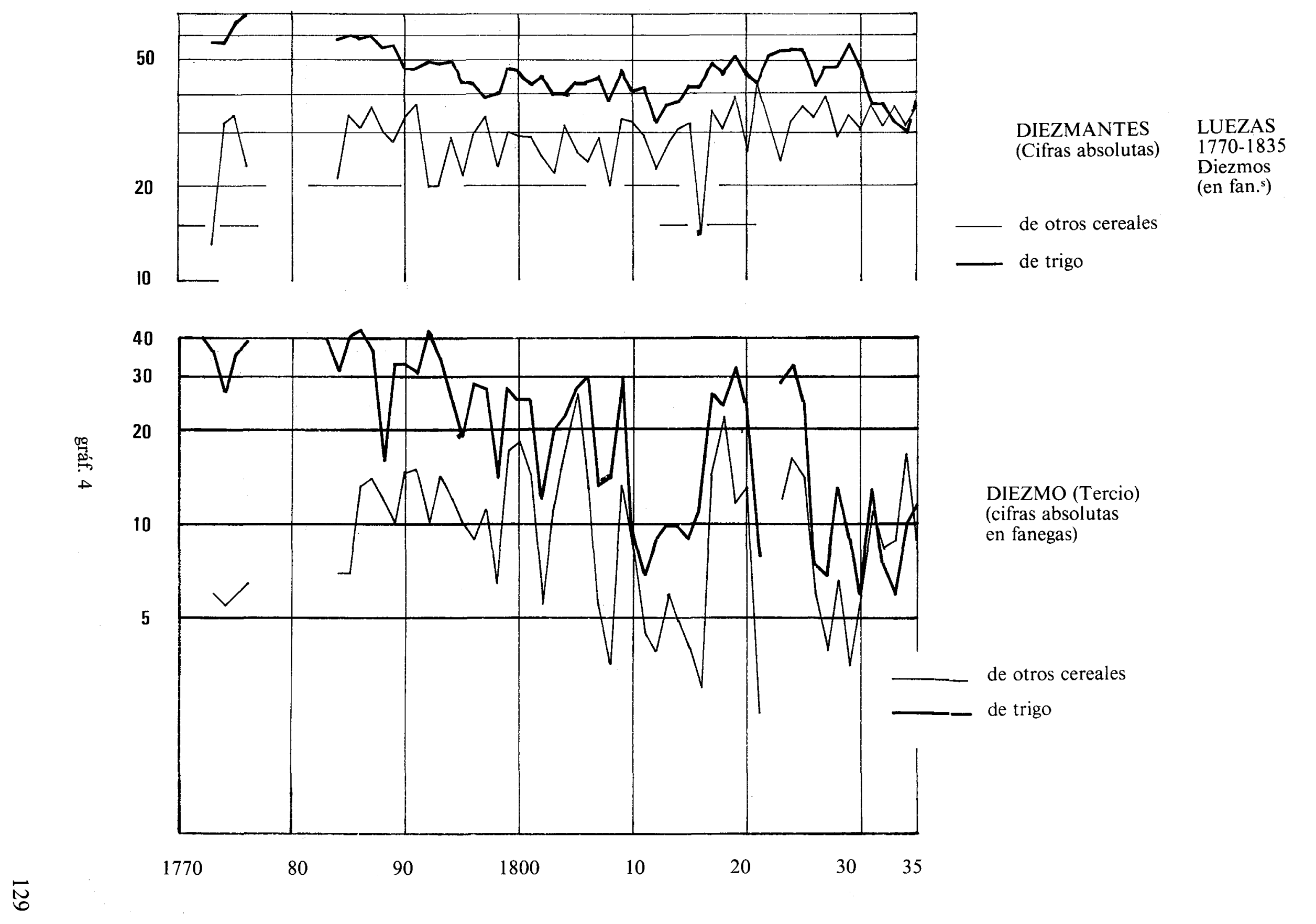




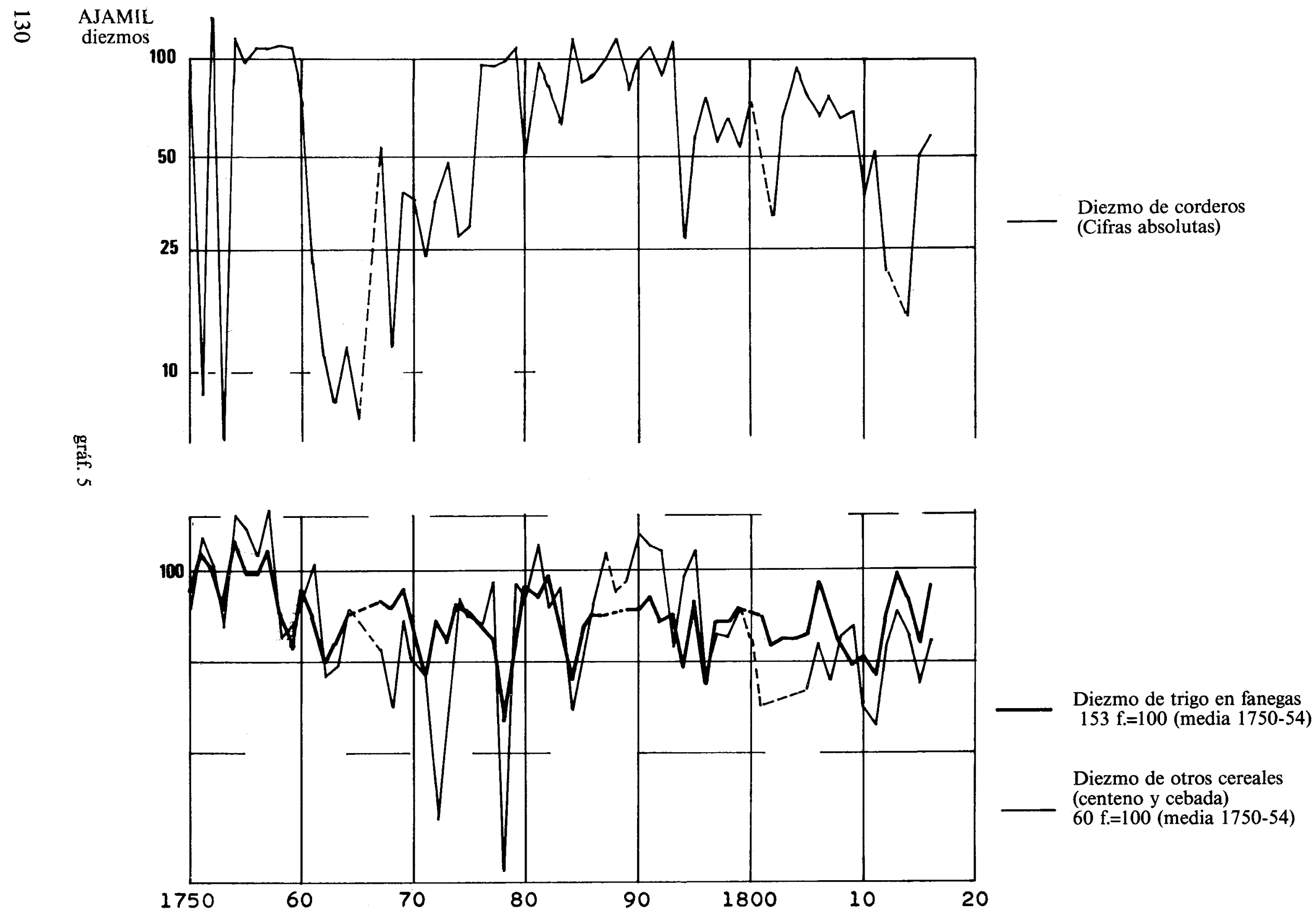




\section{JALON}

diezmos

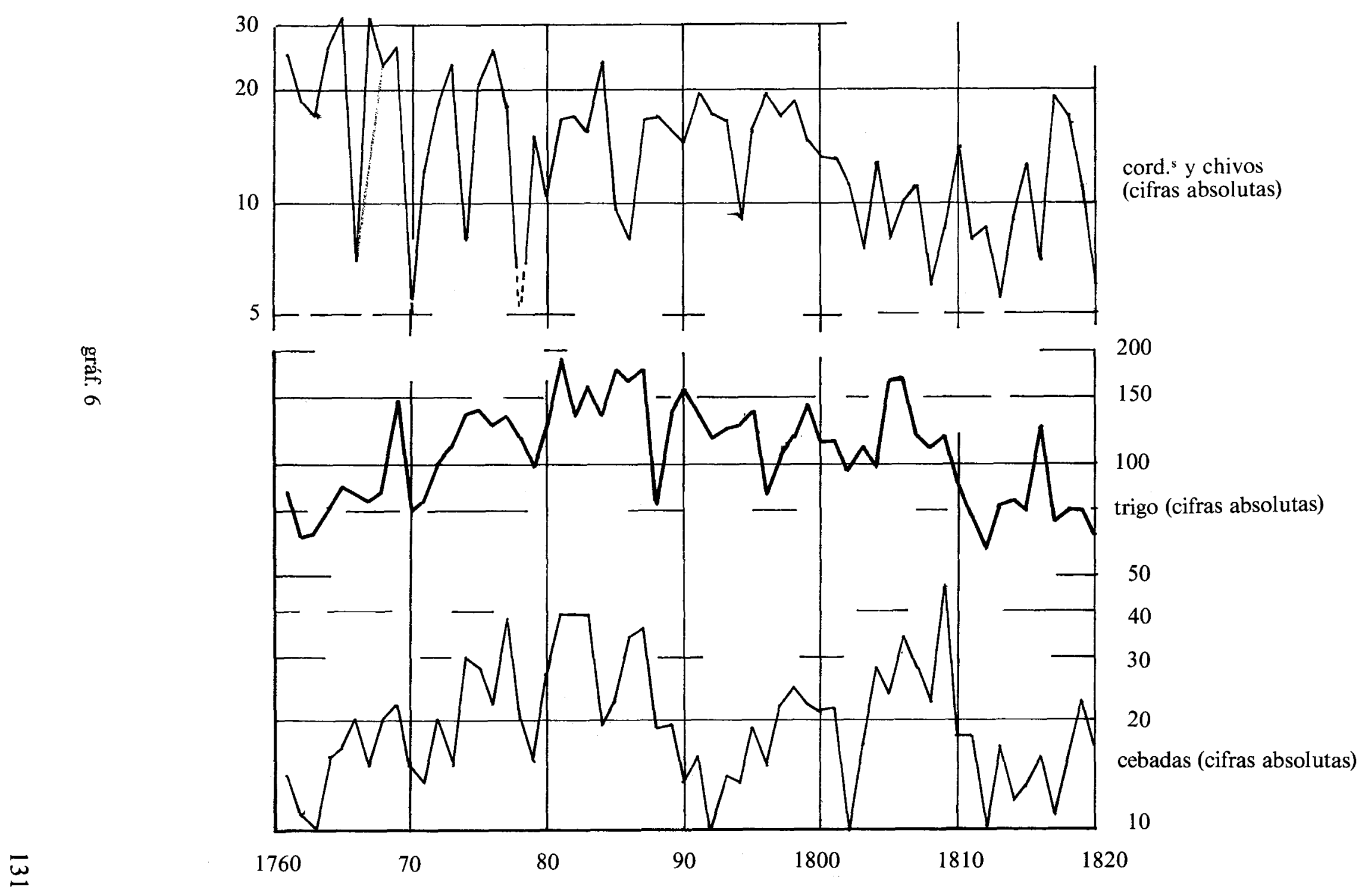


MURO

diezmos

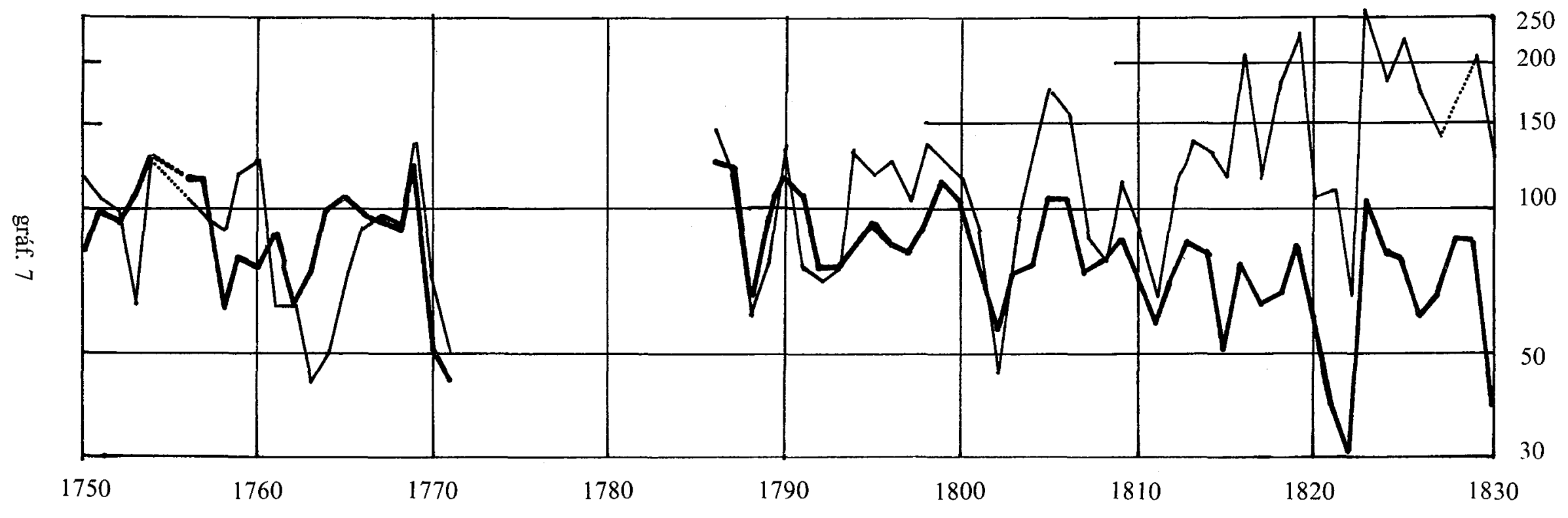

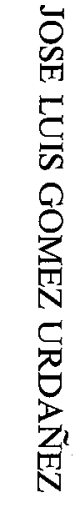

- Trigo. Indice 276 fan=100 (media 1750-1754)

—_ Otros cereales. 44 fan=100 (media 1750-1754) 
SUBSISTENCIA Y DESCAPITALIZACION...

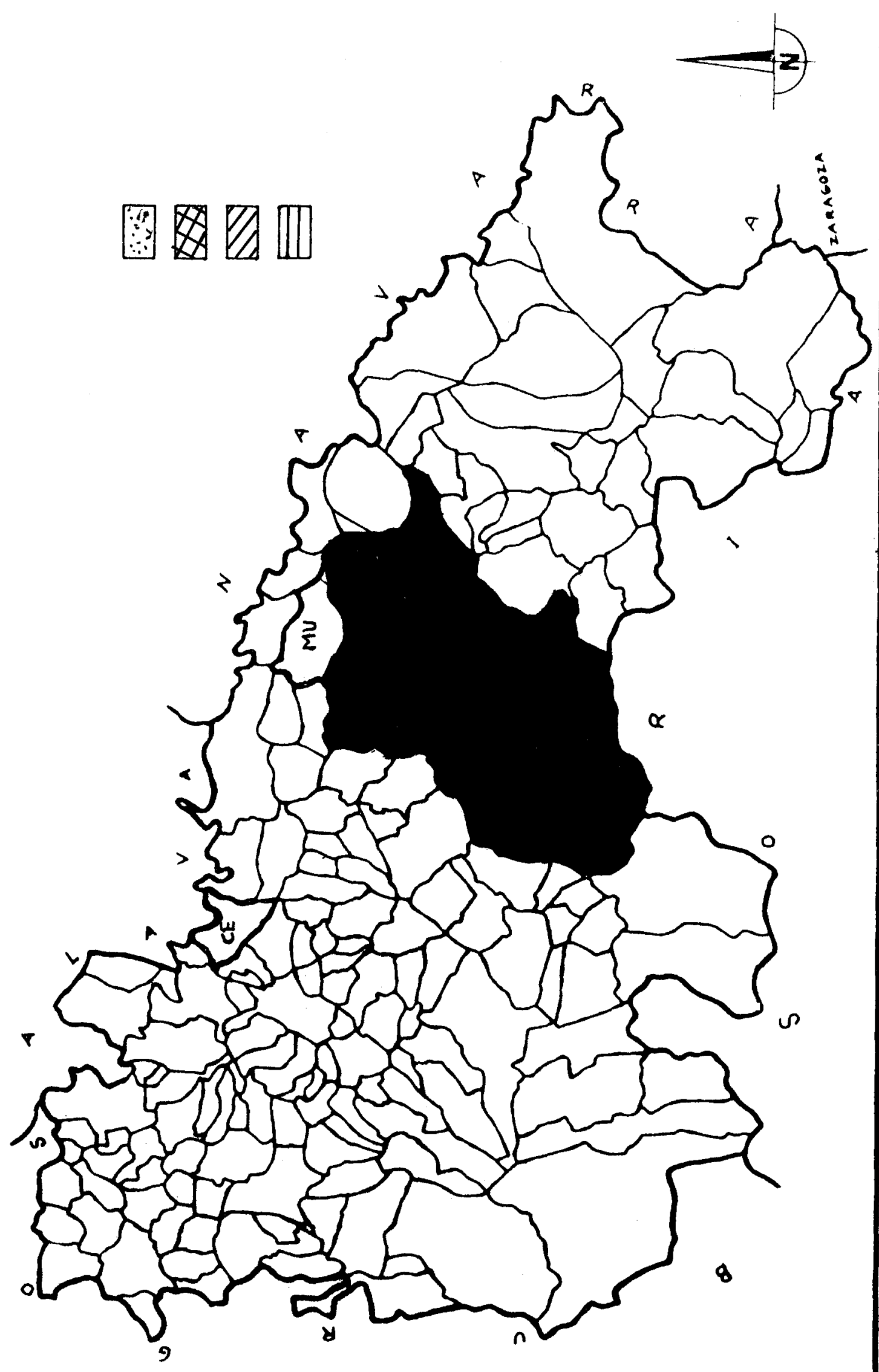




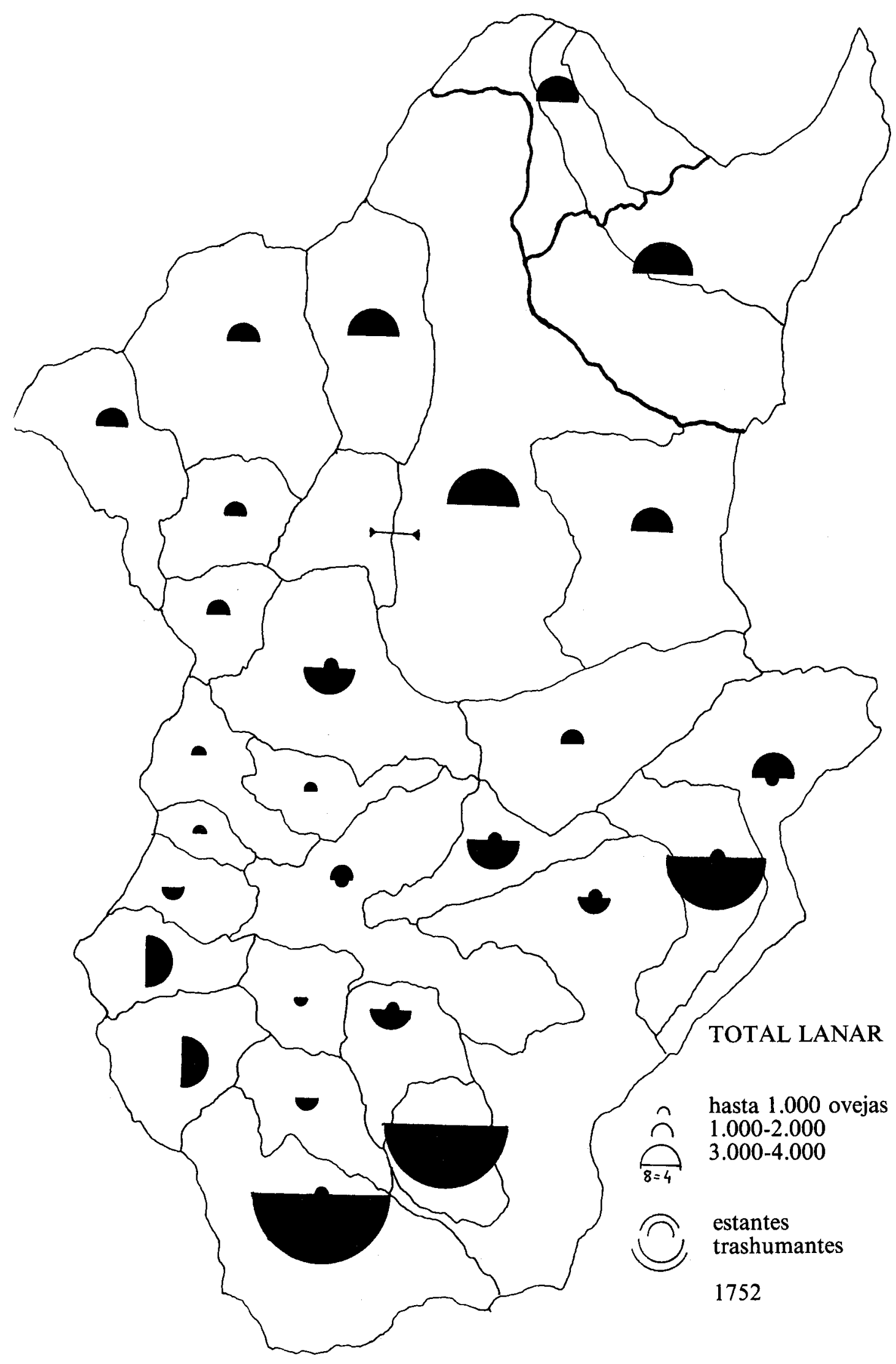

gráf. 8 
cab.s lanar y cabrío por vecino

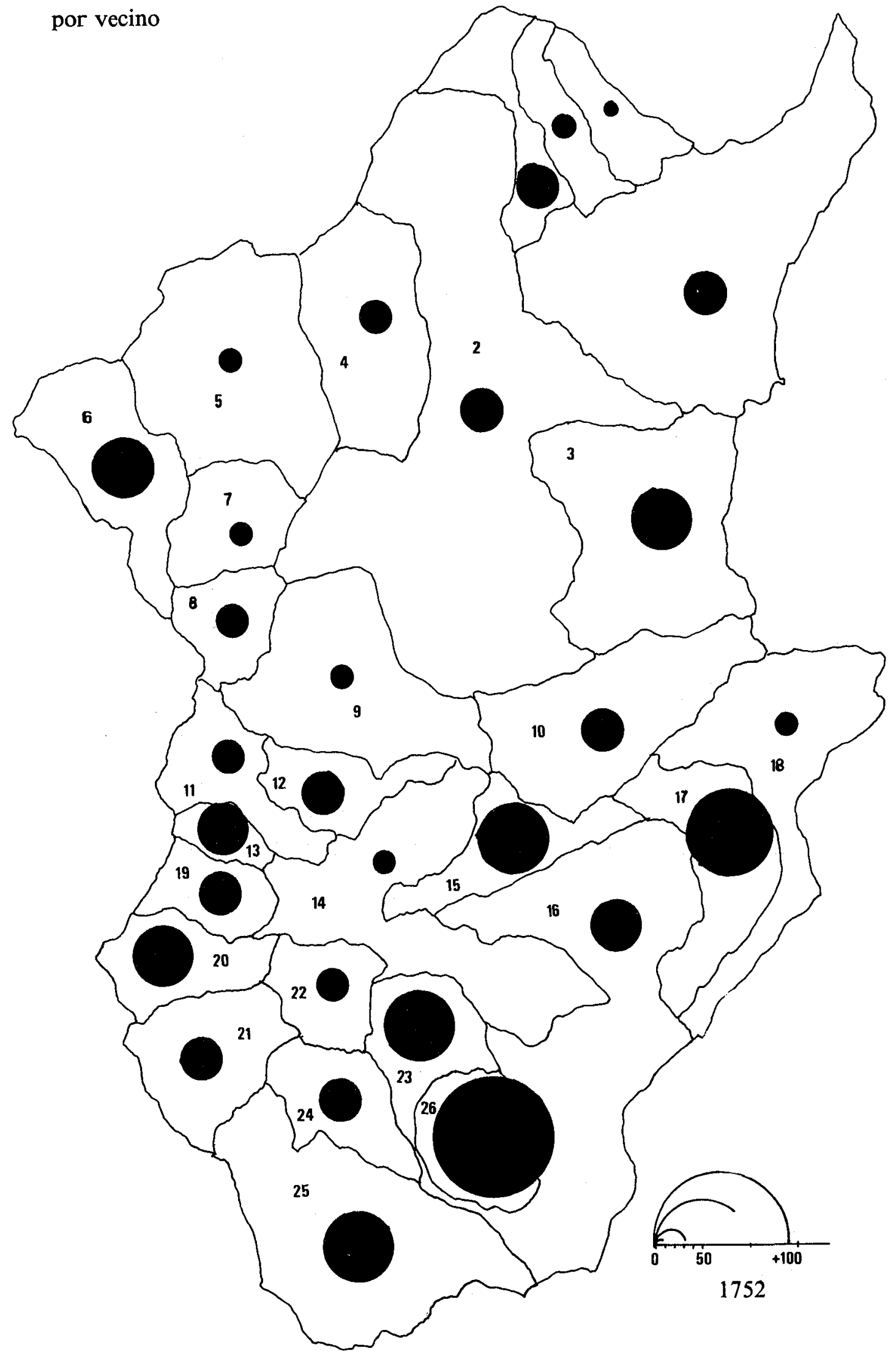

1. Ocón

2. Jubera

3. Robres

4. Lagunilla

5. Ribafrecha

6. Clavijo

7. Leza

8. Trevijano

9. Soto

10. La Santa

11. Luezas

12. Terroba

13. Montalbo

14. San Román

15. Hornillos

16. Larriba

17. Zarzosa

18. Munilla

19. Sta. María

20. Torre

21. Muro

22. Jalón

23. Rabanera

24. Cabezón

25. Laguna

26. Ajamil

gráf. 9 


\section{CONCENTRACION DE LA PROPIEDAD}

\section{GANADERA}

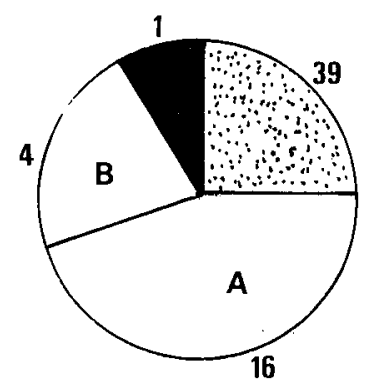

Baja Ocón

Alta Ocón
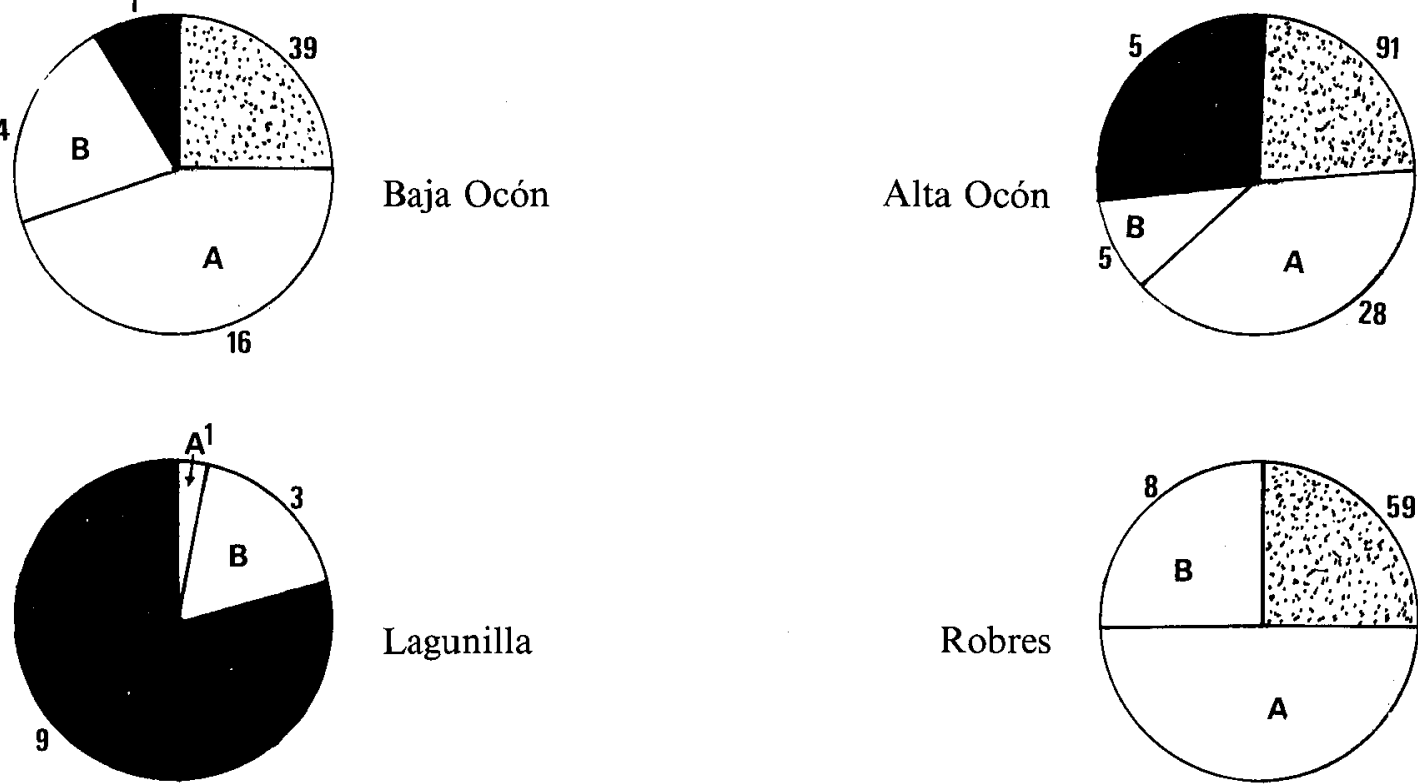

Lagunilla

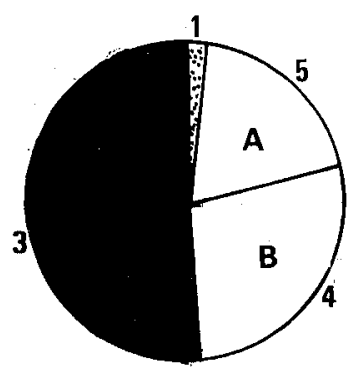

Ribafrecha

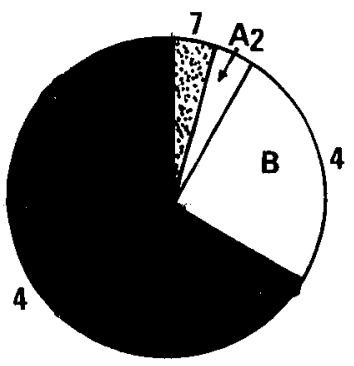

Hornillos

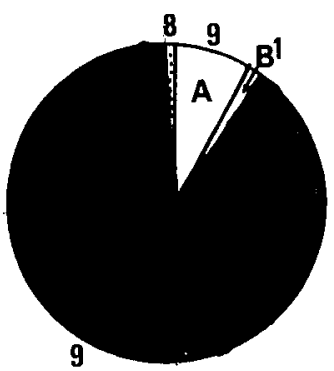

鹿路 pequeños propietarios: rebaños de 0 a $50 \mathrm{cab}^{\mathrm{s}}$

medianos propiet.s:
A rebaños de 51 a 150
B rebaños de 151 a 300

Zarzosa

grandes propietarios: rebaños de más de $300 \mathrm{cab}^{\mathrm{s}}$

$11 \quad \mathrm{n} .{ }^{\circ}$ de propietarios

gráf. 10 


\section{LAGUNA. Pobres socorridos} por dos obras pías

n. ${ }^{\circ}$ de

pobres

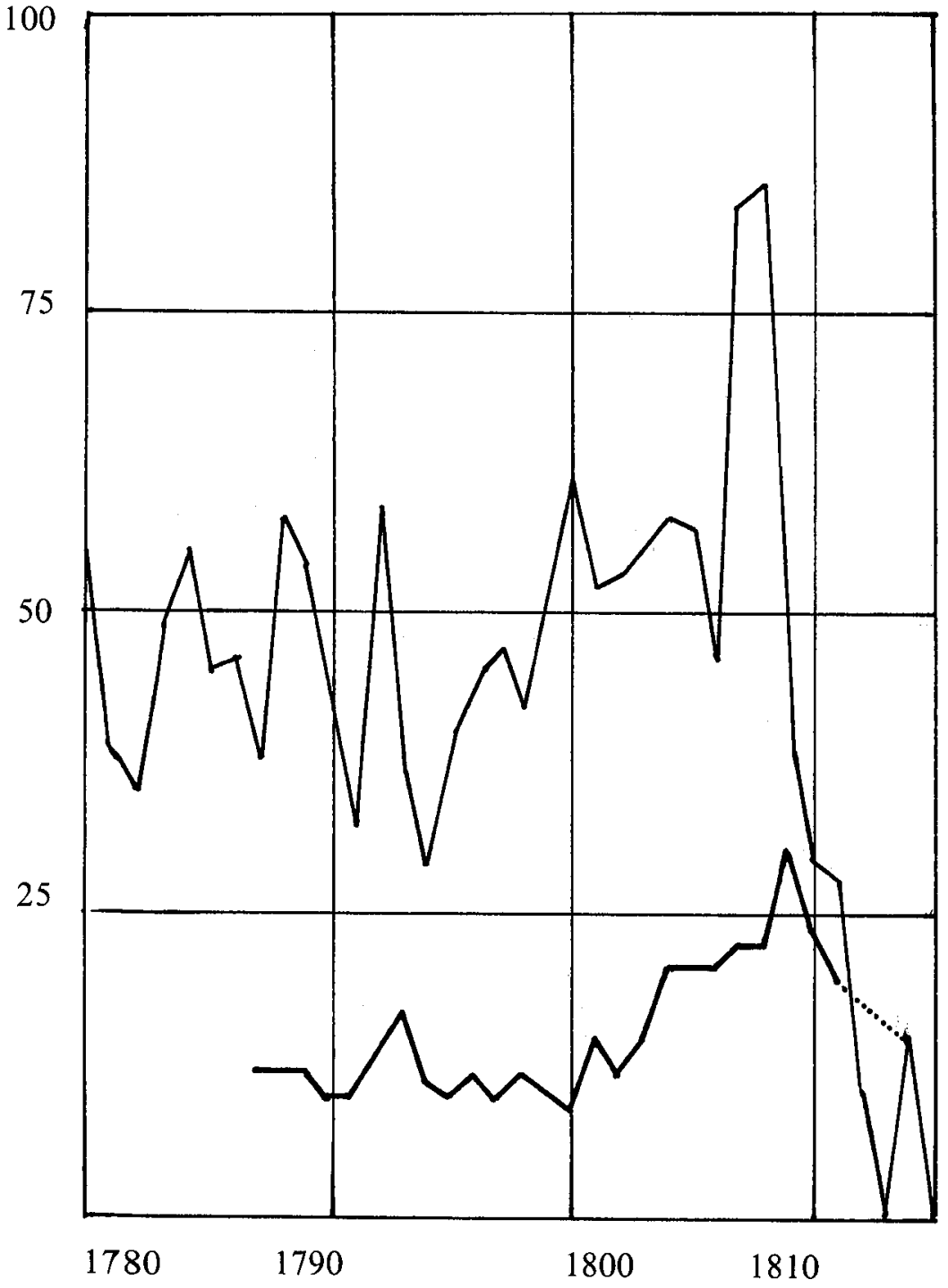

n. ${ }^{\circ}$ pobres socorridos por la Obra Pía de pobres (con dinero)

${ }^{\circ}$ de pobres socorridos por el Arca de Misericordia con los réditos del capital impuesto en la Cía. de Longistas

gráf. 11 


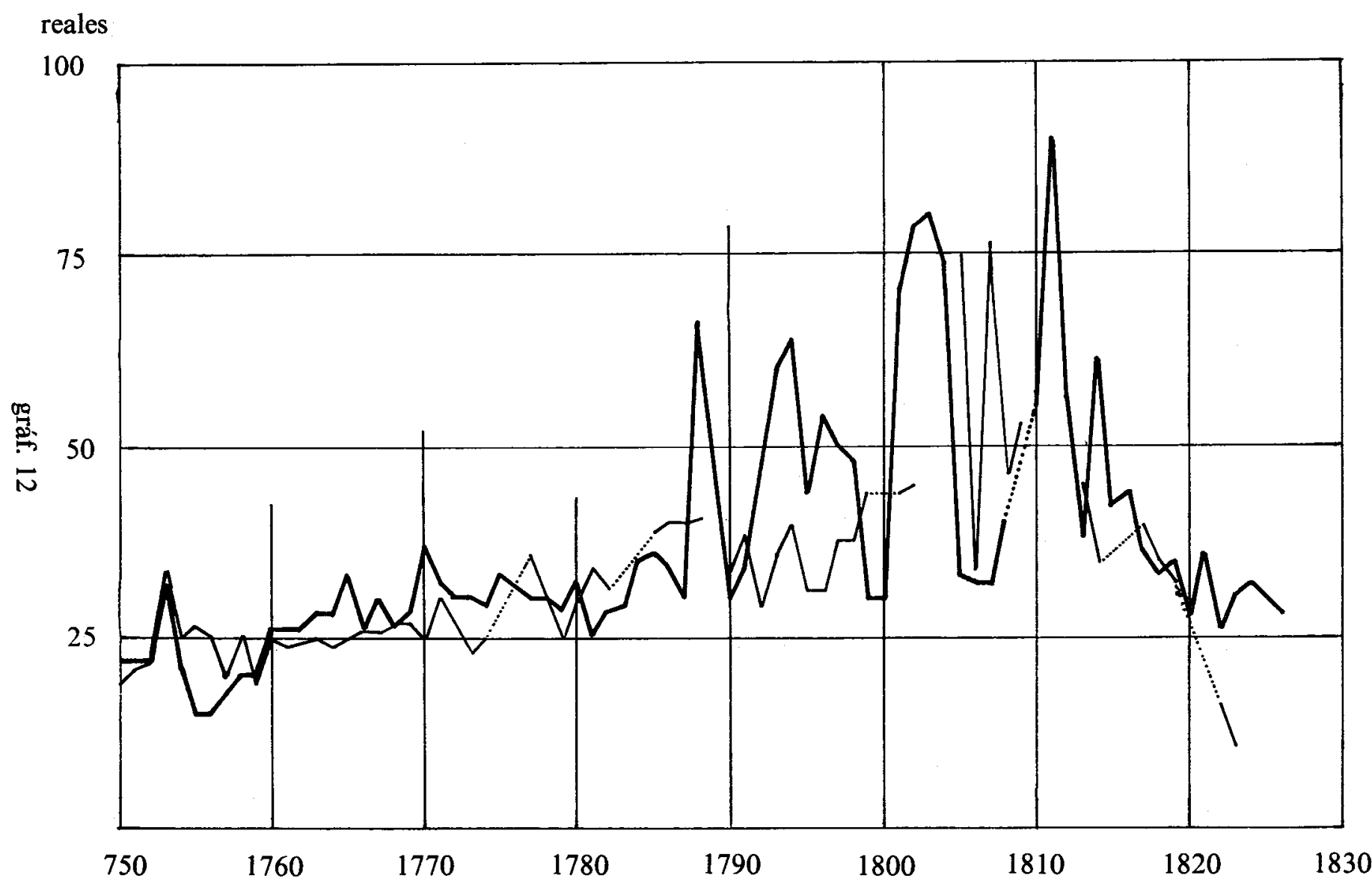

corderos (cifras absolutas en reales/pieza

trigo (cifras absolutas en reales/fanega) 


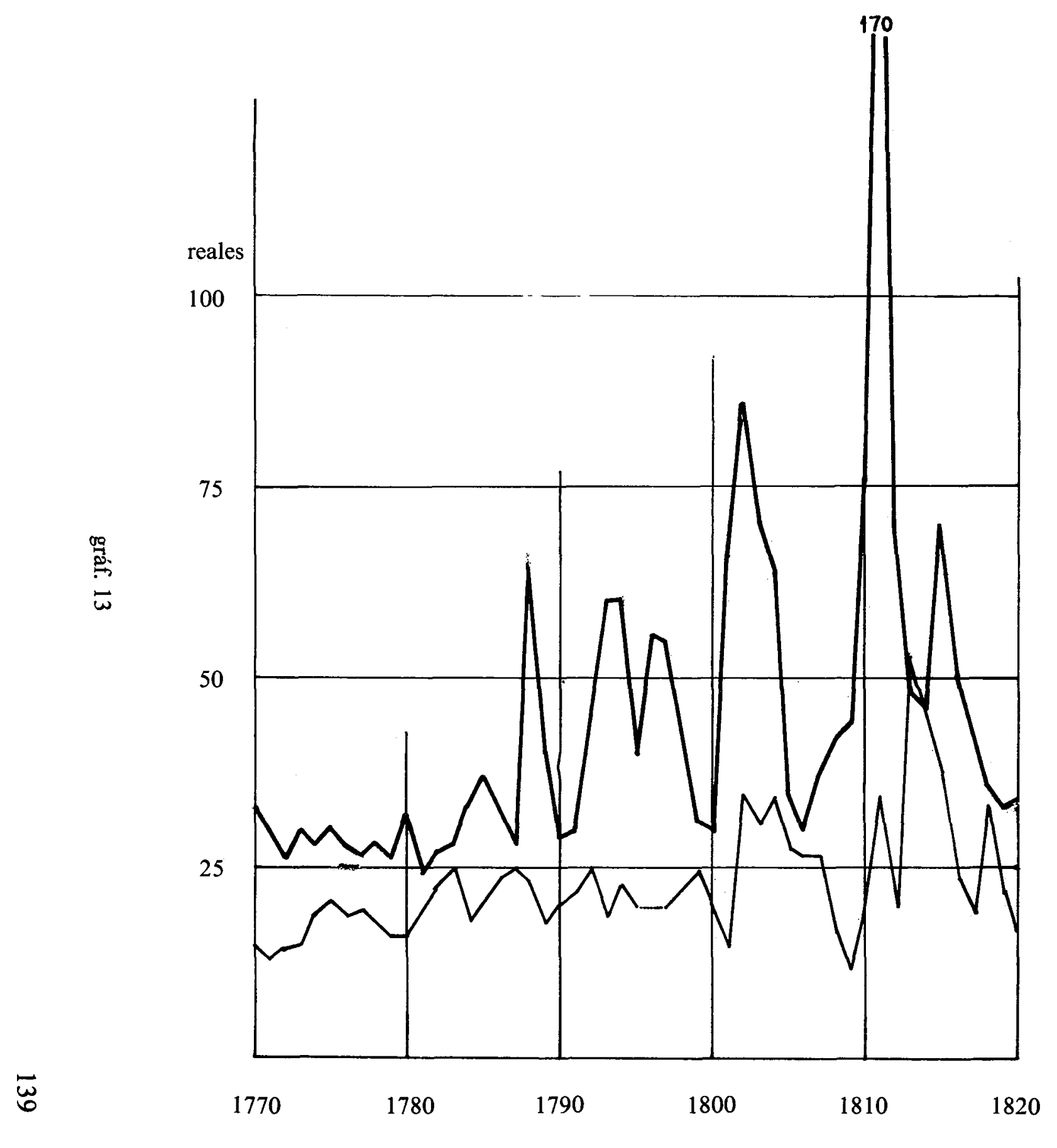

trigo (cifras absolutas en reales/fanega) 
